\title{
Multi-Objective Optimization of Process Parameters in TIG-MIG Welded AISI 1008 Steel For Improved Structural Integrity
}

CYNTHIA SAMUEL ABIMA

University of Johannesburg

STEPHEN AKINWALE AKINLABI

Walter Sisulu University

Nkosinathi Madushele

University of Johannesburg

Olawale Samuel FATOBA ( $\nabla$ drfatobasameni@gmail.com )

University of Johannesburg Faculty of Engineering and Built Environment https://orcid.org/0000-00016931-951X

\section{ESTHER TITILAYO AKINLABI}

Pan African University for Life and Earth Sciences Institute

\section{Research Article}

Keywords: Grey-based Taguchi method, Multi-objective optimization, Tensile strength, TIG-MIG hybrid welding, Yield strength

Posted Date: May 6th, 2021

DOl: https://doi.org/10.21203/rs.3.rs-486430/v1

License: @ (i) This work is licensed under a Creative Commons Attribution 4.0 International License. Read Full License

Version of Record: A version of this preprint was published at The International Journal of Advanced Manufacturing Technology on October 16th, 2021. See the published version at https://doi.org/10.1007/s00170-021-08181-1. 
Multi-Objective Optimization of process parameters in TIG-MIG welded AISI 1008 steel for improved structural integrity

Cynthia Samuel Abima ${ }^{a}$, Stephen Akinwale Akinlabi ${ }^{\mathrm{b}}$, Nkosinathi Madushele ${ }^{\mathrm{a}}$, Olawale Samuel Fatoba $^{\mathrm{c}^{*}}$, Esther Titilayo Akinlabi $^{\mathrm{d}}$

${ }^{a}$ Mechanical Engineering Science, University of Johannesburg, Johannesburg, South Africa. ${ }^{\mathrm{b}}$ Mechanical Engineering, Walter Sisulu University, Butterworth, South Africa

${ }^{\mathrm{c}}$ Kent State University, College of Aeronautics and Engineering, USA.

${ }^{\mathrm{d}}$ Pan African University for Life and Earth Sciences Institute, Ibadan, Nigeria

Cynthia Samuel Abima: oyamacynthiacsa@gmail.com

Stephen Akinwale Akinlabi: stephenakinlabisaa@gmail.com

Nkosinathi Madushele: nmadushelenm@uj.ac.za

Olawale Samuel Fatoba*: drfatobasameni@gmail.com

Esther Titilayo Akinlabi: etakinlabieta@gmail.com 


\begin{abstract}
This study investigates a parametric multi-objective optimization of the Tungsten Inert Gas-Metal Inert Gas (TIG-MIG) hybrid welding of AISI 1008 mild steel joints. A combined grey relational system theory and the Taguchi method was used for process optimization towards achieving a set of process parameter that maximizes both ultimate tensile strength and $0.2 \%$ yield strength for structural applications. An L-9 orthogonal array based on the Taguchi method was adopted for the experimental design matrix. Grey relational grading system was used to establish a single grade for the responses. Mathematical models for first and second-order regression were developed and optimum process parameters combination that optimizes the response were obtained. From the results, the gas flow rate had the most significant influence on the responses with a percentage contribution of $39.77 \%$. Also, the second-order regression models had a higher coefficient of determination $\left(\mathrm{R}^{2}\right)$ compared to the firstorder regression for the two responses and thus, represents the best fit for the process. The grey relational grade was improved by 0.0489 through process optimization. The interactive effects of process parameters and their effects on the responses are also illustrated by response surface plots. This study shows the effectiveness of the grey relational grading system in achieving a multi-objective optimization for the TIG-MIG welding process.
\end{abstract}

Keywords: Grey-based Taguchi method, Multi-objective optimization, Tensile strength, TIG-MIG hybrid welding, Yield strength.

\title{
1. Introduction
}

The quest for high productivity and high-quality welding processes for engineering applications necessitated the modification of the conventional welding processes and the introduction of hybrid welding processes. The hybrid welding processes produce the combined advantages inherent in individual welding processes. Dissimilar metal joints that were rather difficult to join with conventional welding processes have been successfully joined by the hybrid techniques and in most cases show better properties compared to the conventional single welding processes. Several studies have investigated the effectiveness of these hybrids. For instance, Zhang et al. (2017) carried out a comparative study on the joint quality of dissimilar aluminium and titanium welds produced by the Tungsten Inert Gas-Metal Inert Gas (TIG-MIG) double-sided arc welding-brazing process and the MIG welding process. Both welding processes were carried out at the same welding heat input value. From the study, the weld formation and tensile strength in the hybrid process better than those of the conventional MIG weldingbrazing process. Similarly, Ye et al. (2017) also reported that sound and excellent front and back bead 
between aluminium and low carbon steel can be achieved through the MIG-TIG double-sided arc welding process compared to the single MIG welding process, even at lower heat input. The authors claimed that the double-sided arc welding-brazing is more feasible for producing stronger dissimilar joints of mild steel and aluminium. This is because the tensile strength of the hybrid process showed a better value (148 MPa) than that of the single MIG process (56 MPa). The study attributed the high tensile strength of the hybrid process to the even distribution of the welding heat (which helped in impeding intermetallic growth) and the double shielding (which prevented crack formation and pores in the weld).

The advent of hybrid welding in the late 1970s combining high laser welding power with either MIG or TIG arc welding processes have given rise to investigations on the effectiveness of these processes. Such studies of the hybrids have significantly opened-up more spaces for extensive studies of the mechanical and microstructural properties of such hybrids. For instance, Liming et al. (2004), welded AZ31B magnesium alloy by the combined Laser-TIG welding process and individual TIG and Laser welding processes. In the study, the penetration depth of the laser-TIG welding was twice that of the conventional TIG welding process and four times that of single laser beam welding. Similarly, findings to this were reported by Moradi et al. (2018) where the penetration of the Laser-TIG process was twice that of the TIG process and five times that of the laser beam welding. Improved mechanical properties of laser-TIG have also been reported in the literature and this was observed in 304 stainless steel, a study by Yan et al. (2010). The authors compared the tensile strength obtained from the laser-TIG process with those obtained from the individual TIG and Laser welding processes. A better tensile strength was observed in the hybrid compared to the TIG welding, however, the tensile strength of the Laser joint was higher than that obtained from the laser-TIG process. Wang et al. (2020) also reported a 69\% improvement in the tensile strength of laser-TIG welded 6061-T6 compared to the unwelded base material. The authors attributed such improvement in the tensile strength to the formation of fine equiaxed grains and the reduction of beta phase ions in the microstructure of the welds. Similarly, microstructural grain refinement by laser-MIG welding for thick sections of stainless steel was also reported by Zhu et al. (2020). In the study, the grain refinement was supported by the effect of the magnetic field on the weld bead. Also, it has been observed that hybrid welding processes are capable of increasing productivity in welding practices, and this has been investigated in the literature. For instance, Liu et al. (2020) investigated the laser-MIG welding of HG785D steel. They compared the welding speed of the laser-MIG process with that of the single laser process, the welding speed of the hybrid process was seen to be eight times faster than that of the MIG process and resulted in greater productivity. Kang et al. (2018) provided an insight as to which arc of the Laser-TIG welding process should be leading to achieved better joint quality. They investigated the properties of the laser-TIG welding process on 2A14 aluminium when the laser arc was leading and when the TIG arc was leading. The study concluded that under the same welding condition, a leading laser arc result in the increased 
penetration, weld width, and microhardness. This is because the leading laser arc first decomposes the oxidation layer on the plates before the impingement of the TIG arc. Although the laser and plasma power source in combination with either MIG or TIG arc welding produces quality weldments, these processes are complex in operation, difficult to set up, highly capital-intensive and require a high level of expertise. Hence the TIG-MIG hybrid method becomes more attractive because it employs inexpensive techniques, less complicated methods, and finds several applications in the manufacturing industries.

The merits of the TIG-MIG welding process have given rise to several studies in this area aimed at investigating the integrity of the welded joints. For example, Zhou et al. (2017) reported that the MIGTIG method simultaneously combines the high-quality of the TIG welding process and the high efficiency of the MIG welding process in improving weld quality. The authors achieved an ideal front and back weld bead for $24 \mathrm{~mm}$ thick mild steel plates by the hybrid process without the use of backing plates. The combined arc interaction improved the heat distribution at the root weld, leading to complete fusion and higher tensile strength. Also, Kanemaru et al. (2015) alluded to the fact that the MIG-TIG hybrid welding stabilizes the MIG arc even when pure argon gas is used for shielding. To further investigate the hybrid TIG-MIG with their standalone, Zong et al. (2019) conducted a comparative study on the TIG-MIG welding process and the conventional MIG welding. The authors concluded that irrespective of the TIG arc trailing or leading, the hybrid welding speed was faster compared to the conventional MIG welding process. Similarly, Meng et al. (2014) compared the welding speed of the TIG-MIG hybrid process and that of the MIG process while welding mild steel plates for butt joint and bead-on-plate configurations. The TIG-MIG hybrid process had a higher welding speed than the MIG welding process. Cheng et al. (2019) achieved strong connections between copper and stainless steel joined by MIG-TIG double-sided arc welding. All the joints failed in a ductile manner at the copper side of the weldments and this shows that the joints were stronger than the parent copper plates. Also, Ding et al. (2015) proved the stability of the TIG-MIG hybrid method in welding magnesium and ferritic stainless steel with different thickness of copper interlayer. Acceptable shear strengths were obtained, however, the weld with smaller interlayer thickness had the best shear strength. Another comparative study by Ismail et al. (2017) on dissimilar joints of stainless steel and mild steel produced by TIG-MIG hybrid welding, TIG welding, and MIG welding showed that the mechanical integrities of the TIG-MIG welded joints were better than those produced by individual MIG and TIG welding processes. This was accessed through the respective percentage elongation, the tensile strengths, the percentage reduction in area, and the yield strengths obtained from the three types of joints. Zhou et al. (2017) also reported better tensile strength of the TIG-MIG hybrid process. The MIG-TIG welding process was also employed by Zhang et al. (2018) to join aluminium and titanium. In the study, the hybrid process produced a sound dissimilar joint with an excellent front and back weld bead and the dissimilar weld 
joint resulted in the formation of intermetallic compounds. The excessive thickness of the intermetallic compounds led to inherent weld brittleness which resulted in unsatisfactory weld integrity.

Several input parameters significantly contribute to the quality of the TIG-MIG hybrid joints. The selection of appropriate input process parameters to achieve desirable characteristics plays a significant role in cost minimization and product quality. The right combination of these input parameters becomes an uphill task with significant cost implications. Due to the numerous and complex interaction of input process parameters in the TIG-MIG hybrid welding process, optimization of input process parameters becomes the key step in achieving high quality and improve performance characteristics without increasing the cost. The TIG-MIG welding process optimization is still being studied. Even though many studies aim at weld characterization, few exist that focussed on process optimization. Among these few include the study by Khan et al. (2018) where the authors applied the Non-dominated Sorting Genetic Algorithm to optimize the bead width and hardness of TIG-MIG hybrid welded stainless steel. The increase in the gas flow rate resulted in a decrease in the hardness value and a small increase in the bead width. Excessive gas flow rate resulted in an unstable arc. The authors suggested that the gas flow rate, voltage and current should be maintained at 15-17 (L/min), 24 (V) and 200 (A) respectively to achieve the best combination of hardness and bead width. Also, Schneider et al., (2017) focused on the parametric optimization of the TIG-MIG hybrid process for improved weld bead geometry using the Taguchi method. The MIG welding voltage, TIG welding electric current, gas type, gas flow rate, welding speed and wire feed rate of the MIG process were the selected input factors. The TIG welding intensity, the MIG voltage and the welding speed are identified as the input factors which had the most influence on the weld geometry. The authors, however, suggested that the influence of other factors such as torch angle and distance between wire and electrode on the weld geometry should be studied. Alluding to this, Meng et al. (2014) studied the influence of TIG welding current, TIG welding torch angle, MIG welding torch angle, wire-electrode distance, and height of tungsten electrode in high-speed TIG-MIG welding of mild steel and optimized the weld bead appearance. The analysis indicated that the wire-electrode distance and the TIG welding current were the most influential factors on the weld appearance. However, optimization of weld bead appearance is not sufficient to determine the integrity of the TIG-MIG hybrid process for structural applications. Somani and Lalwani, (2019) optimized the input process parameters of TIG-MIG hybrid welded austenitic stainless steel of $8 \mathrm{~mm}$ thick plates with the ultimate tensile strength as the response variable. From the study, it was observed that the welding currents had the most significant influence on the ultimate tensile strength of the welds.

Even though few studies have investigated process optimization in TIG-MIG welding, such studies attempt to optimize the weld bead geometry and the tensile strength of weldment independently. In the reality, multiple material properties are often desired for satisfactory performance thus leaving a tradeoff between each objective. Unfortunately, a multi-objective optimization approach to input parameters of the TIG-MIG welding process has not been given attention in the literature. Consequently, more 
studies are needed in this direction to establish the process window for optimum parametric set up to achieve better joint properties with enhanced structural integrity. In this case, the Grey Relational Analysis (GRA) becomes a useful tool in solving multi-objective and complicated optimization simultaneously. The GRA is used to convert the multi-objective responses to a single grade response called the Grey Relational Grade (GRG). The frequently used Taguchi method for welding process optimization has been observed to be inadequate in solving problems involving multiple responses. This problem is overcome by integrating the Taguchi method with grey relational analysis as alluded to by Wakchaure et al. (2018). A notable study where this technique has been utilized is in a study by Avinash et al. (2019). The authors performed parametric optimation of dissimilar AISI 304 steel and Monel 400 joint produced by pulsed TIG welding to maximise the tensile strength and percentage elongation and minimise the heat-affected zone of the weldment using the GRG obtained from GRA based on the L-9 Taguchi method. The optimum process parameter combination for the desired responses based on the GRG was peak current at $180 \mathrm{~A}$, base current at $90 \mathrm{~A}$ and frequency at $4(\mathrm{~Hz})$. Analysis of variance reveals that the pulse frequency had the most influence on the GRG with a 53.05\% contribution. Also, a confirmatory test performed with the optimum process parameters indicates an increase in the tensile strength and the percentage elongation and a reduction in the heat-affected zone of the weldment. However, the authors did not validate the process to justify an improvement in the GRG. Haq et al. (2008) also employed the GRA and Taguchi method to performed multi-objective optimization by converting the responses into a single GRG and affirms that the technique was efficient in predicting the surface roughness, torch value and the cutting force of the process as the GRG was improved by $2 \%$ following the confirmatory test. Also, Srirangan and Paulraj (2016), carried out simultaneous optimization of tensile strength, yield strength and impact strength to determine the set of process parameters that will maximize the GRG. The input parameters selected were the welding voltage, current and welding speed. Each input parameter was set at three levels. A medium current and welding speed with low voltage maximised the GRG. Analysis of variance showed that the welding current had the most influence on the GRG with a $58 \%$ contribution.

With the quest for quality weldments in structural engineering, multi-objective problems involving optimal yield strength and tensile strength and is often faced in the reality. Hence, to avoid catastrophic failure, engineers often design components with the material yield strength and oftentimes with reference to $0.2 \%$ yield strength. While other studies have investigated these multiple problems as single objective functions, to the best of our knowledge, there have been no studies that investigated the two objectives using a multi-objective optimization approach. This study, therefore, investigates the ultimate tensile strength and the $0.2 \%$ yield strength of the TIG-MIG hybrid welding process. Multiobjective optimization of the process parameters was further investigated using the grey-based Taguchi method to determine the process parameter combination that will optimize the ultimate tensile strength and the $0.2 \%$ yield strength. While this section presents a background to the study, section 2 presents 
the materials and methodology used for the multi-objective optimization process and statistical analysis. Section 3 presents the results obtained from the analyses including surface plots showing the relationships between responses and input variables and section 4 concludes the study.

\section{Materials and Methods}

\subsection{Materials}

The base material used in this work is AISI 1008 mild steel with dimensions of $150 \times 100 \times 6 \mathrm{~mm}^{3}$. ER $70 \mathrm{~S} / 6$ carbon filler rod of $2.4 \mathrm{~mm}$ diameter was used as filler material. The chemical compositions of AISI 1008 and the ER 70S/6 filler rod are presented in Table 1 and Table 2 respectively.

Table 1. Chemical composition of AISI 1008

\begin{tabular}{lllllllllll}
\hline $\begin{array}{l}\text { Element } \\
\text { symbol }\end{array}$ & $\mathbf{C}$ & $\mathbf{S}$ & $\mathbf{P}$ & $\mathbf{M n}$ & $\mathbf{S i}$ & $\mathbf{C r}$ & $\mathbf{M o}$ & Ni & Al & Fe \\
\hline $\begin{array}{l}\text { \% by } \\
\text { weight }\end{array}$ & $0.072-$ & 0.0091 & 0.0098 & 0.32 & 0.068 & 0.042 & 0.005 & 0.0064 & 0.042 & Bal \\
\hline
\end{tabular}

Table 2. Chemical composition of ER70S/6 filler metal

\begin{tabular}{|c|c|c|c|c|c|c|c|c|c|}
\hline $\begin{array}{l}\text { Element } \\
\text { symbol }\end{array}$ & C & $\mathbf{N i}$ & Mn & $\mathrm{Cr}$ & $\mathbf{S i}$ & $\mathbf{S}$ & $\mathbf{V}$ & Mo & $\mathrm{Cu}$ \\
\hline $\begin{array}{l}\text { \% by } \\
\text { weight }\end{array}$ & $\begin{array}{l}0.06- \\
0.15\end{array}$ & $0.15 \max$ & $\begin{array}{l}1.4- \\
1.85\end{array}$ & $0.15 \max$ & $0.8-1.15$ & $0.035 \max$ & $0.03 \max$ & $0.15 \max$ & 0.5 \\
\hline
\end{tabular}

\subsection{Identifying control factors and response parameters}

In welding operations, they are numerous input process parameters, otherwise called the control factors which influence the quality of welds produced. These factors are called control factors because they can be controlled by the welder before and during the welding operation. Because the choice of factors directly influences the quality of the welds produced, it becomes imperative to make proper choices. In this experiment, the TIG welding process is of the constant current characteristic, while the MIG welding process is of the constant voltage characteristic. Therefore, the TIG welding current was set and the TIG voltage corresponded to the set current based on the distance maintained between the workpiece and the tungsten electrode. Likewise, in the MIG welding process, the MIG welding voltage was set and the MIG welding current was matched with the set MIG voltage based on the wire feed rate. Hence the heat input of the two welding processes is controlled by these characteristics. The selected control factors referred to as input process parameters in this experiment are: the TIG welding 
current, the MIG welding voltage, and the gas flow rate. The weld characteristics responses considered in this work are the ultimate tensile strength and the yield strength of the weldments.

\subsection{The Taguchi design of experiment}

The Taguchi design of experiment method was adopted in this work to define the design matrix of the input process parameters. Three input process parameters at three levels were chosen and presented in Table 3.

Table 3. Input process parameters and their levels

\begin{tabular}{llllll}
\hline $\begin{array}{l}\text { Serial } \\
\text { No }\end{array}$ & Factors & Unit & Level 1 & Level 2 & Level 3 \\
\hline 1 & & & & \\
2 & Voltage (MIG) & Volts (V) & 20 & 25 & 30 \\
3 & Current (TIG) & Ampers (A) & 140 & 160 & 180 \\
\hline
\end{tabular}

The range of values of the MIG welding voltage denoted by voltage (MIG), the TIG welding current denoted by current (TIG), and the gas flow rate have been chosen based on literature review and welder experience. The effects of the various process parameter combination on the characteristic response of the welds produced were investigated. An L-9 Taguchi orthogonal array $\left(3^{3}\right.$ i.e. three factors at three levels) which allows for easier computation, time, and cost-saving is adopted in this work and presented in given in Table 4.

Table 4. Experimental design matrix

\begin{tabular}{llll}
\hline \multirow{2}{*}{$\begin{array}{l}\text { Sample } \\
\text { Run }\end{array}$} & \multicolumn{3}{c}{ Input process parameters } \\
\cline { 2 - 4 } & Voltage (MIG) & Current (TIG) & Gas flow rate \\
\hline 1 & 20 & 140 & 17 \\
2 & 20 & 160 & 19 \\
3 & 20 & 180 & 17 \\
4 & 25 & 140 & 19 \\
5 & 25 & 160 & 15 \\
6 & 25 & 180 & 19 \\
7 & 30 & 140 & 15 \\
8 & 30 & 160 & 17 \\
9 & 30 & 180 &
\end{tabular}




\subsection{Sample preparation and welding procedures}

To eliminate weld contamination due to the presence of accumulated rust on storage, oil, grease, and any other form of impurity on the surface of the weld, a small hand grinding machine was used to remove the oxide layer and acetone was used to cleanse the surface of the plate.

A total of 9 sample runs defined in Table 4 were TIG-MIG hybrid welded in the butt-joint configuration. The hybrid welding was achieved by first producing the TIG pass followed by the MIG pass. The TIG welding process is of the constant current characteristic, while the MIG welding process is of constant voltage characteristic. A tungsten electrode of $3.2 \mathrm{~mm}$ was used with an ER 70S/6 carbon filler rod of $2.4 \mathrm{~mm}$ as a filler material. A root gap of $2.5 \mathrm{~mm}$ was maintained between plates for all welds.

\subsection{Analytical methods}

The grey-based Taguchi method was employed to perform multi-objective optimization of TIG-MIG hybrid process parameter for welding AISI 1008 mild steel to determine the process parameter combination which will optimize the overall quality characteristics (the tensile strength and the $0.2 \%$ yield strength). The grey relational analysis is a useful tool for measuring the degree of the relationship between sequences. It is used to transform multiple output responses into a single output response by designating Grade Relational Grade (GRG) to discrete output responses. Several researchers have employed grey relational analysis to optimise process parameters for multi-objective response through grey relational grade (Mathew and Rajendrakumar, 2011). The Minitab 17 software was used to determine the signal to noise ratio $(\mathrm{S} / \mathrm{N})$ and to determine the optimum process parameter combination from the 9 sample runs that maximize the output response in terms of the grey relational grade (GRG) based on the-higher-the-better criteria. Analysis of variance (ANOVA) was carried out to determine the percentage contributions of the input process parameters on the GRG.

\section{Results and discussion}

\subsection{Tensile results}

Tensile testing is one of the most important tests carried out to determine the mechanical properties of engineering materials. The assessment of weld quality in terms of these mechanical properties is important to ascertain the reliability of the weld for structural applications. Tensile testing was conducted using the Zwick Roell 2250 tensile testing machine. All test samples were machined according to ASTM E8 and subjected to a gradual increase in load until failure occurred. The tensile test specimen sketch is shown in Figure 1. 


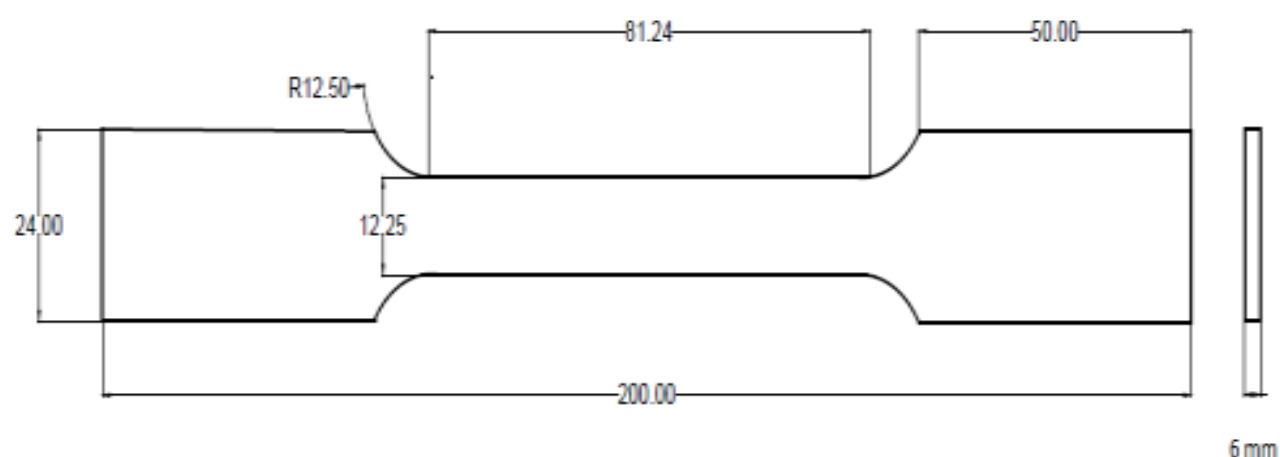

Figure 1. The tensile test specimen sketch

The ultimate tensile strength (UTS) and the $0.2 \%$ yield strength (YS) are considered for evaluation in this study. The results are presented in Table 5.

Table 5. Experimental results (ultimate tensile strength and the yield strength)

\begin{tabular}{llllll}
\hline $\begin{array}{l}\text { Sample } \\
\text { runs }\end{array}$ & Voltage (MIG) & Current (TIG) & Gas flow rate & UTS (MPa) & YS (MPa) \\
\hline 1 & 20 & 140 & 15 & & \\
2 & 20 & 160 & 17 & 850.88 & 667.66 \\
3 & 20 & 180 & 19 & 851.23 & 664.66 \\
4 & 25 & 140 & 17 & 861.74 & 681.65 \\
5 & 25 & 160 & 19 & 863.67 & 657.03 \\
6 & 25 & 180 & 15 & 851.31 & 684.26 \\
7 & 30 & 140 & 19 & 850.58 & 674.20 \\
8 & 30 & 160 & 25 & 848.93 & 666.42 \\
9 & 30 & 180 & 17 & 727.27 & 615.12 \\
\hline
\end{tabular}

All the weldment showed good tensile property as they all failed in a ductile manner at the base material region of the specimens. This means that the welded joint had higher strength compared to the parent material. This result is very credible, as oftentimes, welded joints are usually seen to be weaker having lower tensile strength compared to their unwelded base material counterpart. More so, the fusion welding process generally introduces a considerable large amount of heat into the material resulting in a high-temperature field. The high-temperature field and cooling process during arc welding may cause deterioration of the mechanical properties of weldments. The fractured specimens are shown in Figure 2. 


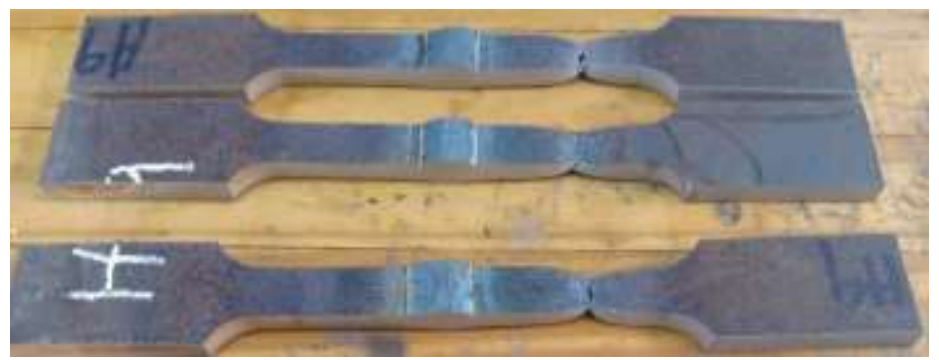

Figure 2. Fractured specimens

From Table 5, the highest ultimate tensile is $863.67 \mathrm{MPa}$ and corresponds to run 4 and the lowest ultimate tensile strength is $727 \mathrm{MPa}$ and corresponds to run 8. The maximum yield strength is 684.26 MPa corresponding to run 5, and the lowest is $615.12 \mathrm{MPa}$ seen for weld run 8 . The ultimate tensile strength and the yield of the base material are $406 \mathrm{MPa}$ and $307 \mathrm{MPa}$ respectively. It becomes obvious from the results that the ultimate strength for all TIG-MIG hybrid welding doubles that of the parent material except for run 8, and yield strength for all runs of the TIG-MIG hybrid joints doubles those of the parent material. The stress-strain diagram for sample run 4 and weld run 7 are presented in Figure 3 (a) and (b). The $0.2 \%$ offset yield strength for weld run 7 and weld run 3 are presented in Figures 4(a) and (b).

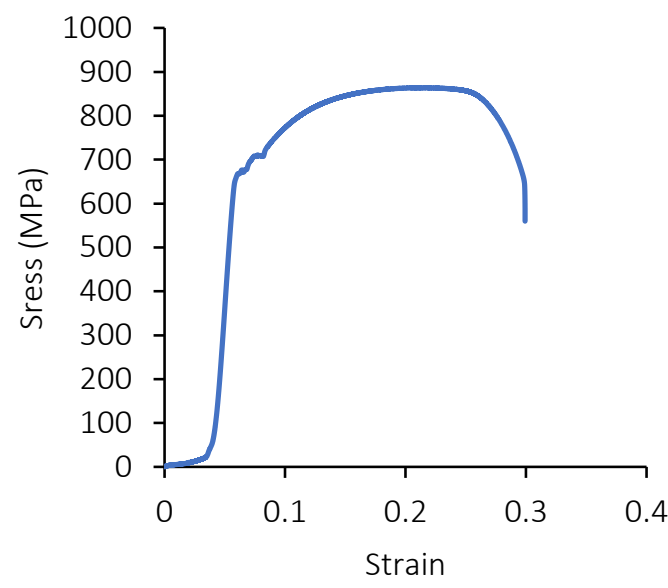

(a)

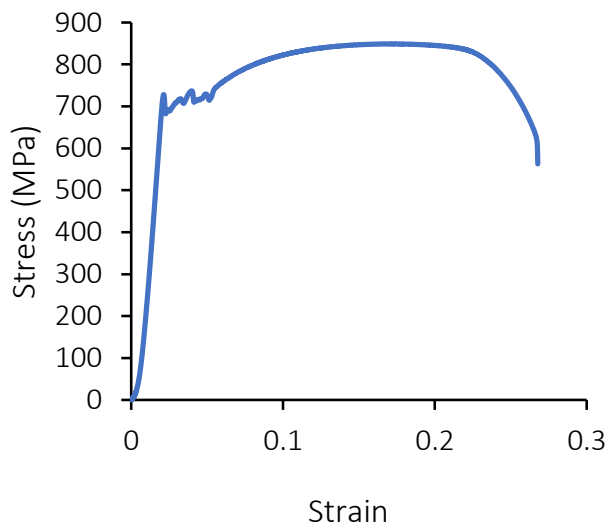

(b)

Figure 3. Stress-strain curve (a) sample run 4 (b) sample run 7 


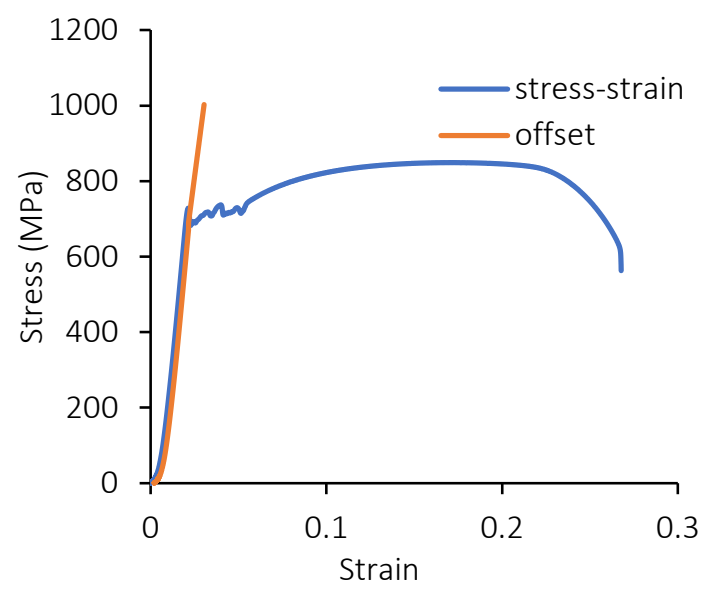

(a)

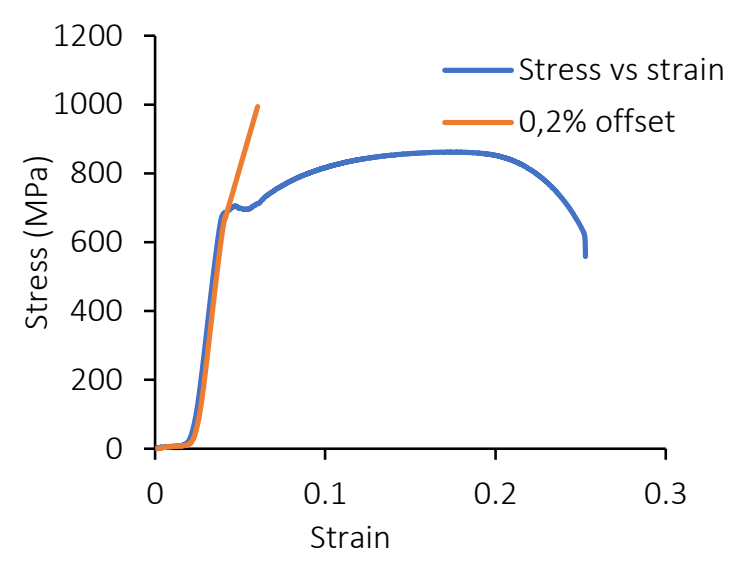

(b)

Figure 4. Offsets obtained from the original stress-strain curve (a) $0.2 \%$ offset yield strength for sample 7 (b) $0.2 \%$ offset yield strength for sample 3

\subsection{Grey relational analysis}

The grey-based Taguchi method is used in this work to determine the optimum process parameter combination that maximizes the desired responses. The larger-the-better objective function is used for the optimization process and data analysis. To perform the grey relational analysis, the experimental data is first normalized to range between 0 to 1, based on the larger-the better-function using Equation 1. The data normalizing is followed by computing the deviation sequence of the set of data using Equation 2. The grey relational coefficient, the grey relational grades (GRG) are obtained using Equation 3, and 4, respectively. Table 6 shows the data for the grey-relational analysis.

To normalize experimental data (criterion - the larger the better)

$x_{i}^{*}(k)=\frac{x_{i}(k)-\operatorname{Min} x_{i}(k)}{\operatorname{Max} x_{i}(k)-\operatorname{Min} x_{i}(k)}$

Where $x_{i}^{*}(k)$ is the normalized value, $x_{i}(k)$ is the target value, $\operatorname{Min} x_{i}(k)$ is the lowest value of $x_{i}(k)$, and $\operatorname{Max} x_{i}(k)$ is the highest value of $x_{i}(k)$

$i=1,2,3 \ldots, \mathrm{m} . \quad$ and $\mathrm{k}=1,2,3 \ldots, \mathrm{n}$.

$\mathrm{m}$ and $\mathrm{n}$ denote the number of experimental data and the number of responses, respectively.

To derive the grey relational coefficient

$\xi_{i}(k)=\frac{\Delta_{\operatorname{Min}}+\xi \Delta_{\operatorname{Max}}}{\Delta_{o i}+\xi \Delta_{\operatorname{Max}}}$ 
Where $\xi_{i}(k)$ is the grey coefficient, $\Delta_{o i}$ is the deviation sequence, $\Delta_{\text {Min }}$ and $\Delta_{\text {Max }}$ are the minimum and maximum values of $\Delta_{o i}$ for all the sequences and $\xi$ is the identification coefficient. In this work, 0.5 is used as the identification coefficient used to generate equal weightage for both quality response parameters.

To get the Deviation sequence

$\Delta_{o i}=\left\|x_{o}(k)-x_{i}(k)\right\|$

To find out the grey relational grade

$y_{i}=\frac{1}{n} \sum_{k-1}^{n} \xi_{i}(k)$

Where $y_{i}$ is the GRG for the ith experimental run, and $\mathrm{n}$ is the number of characteristic response.

Table 6. Grey relational analysis

\begin{tabular}{|c|c|c|c|c|c|c|c|c|c|c|}
\hline \multirow[t]{2}{*}{$\begin{array}{l}\text { Sample } \\
\text { Runs }\end{array}$} & \multicolumn{2}{|c|}{ Responses } & \multicolumn{2}{|c|}{$\begin{array}{l}\text { Normalized } \\
\text { values }\end{array}$} & \multicolumn{2}{|c|}{$\begin{array}{l}\text { Sequence } \\
\text { deviation }\end{array}$} & \multicolumn{2}{|c|}{$\begin{array}{l}\text { Grey relational } \\
\text { coefficient }\end{array}$} & \multirow[t]{2}{*}{$\begin{array}{l}\text { Grey relational } \\
\text { Grade }\end{array}$} & \multirow[t]{2}{*}{ Rank } \\
\hline & UTS & YS & UTS & YS & UTS & YS & UTS & YS & & \\
\hline 1 & 850.88 & 667.66 & 0.906 & 0.760 & 0.094 & 0.240 & 0.842 & 0.676 & 0.759 & 6 \\
\hline 2 & 851.23 & 664.66 & 0.909 & 0.717 & 0.091 & 0.283 & 0.846 & 0.638 & 0.742 & 7 \\
\hline 3 & 861.74 & 681.65 & 0.986 & 0.962 & 0.014 & 0.038 & 0.972 & 0.930 & 0.951 & 1 \\
\hline 4 & 863.67 & 657.03 & 1.000 & 0.606 & 0.000 & 0.394 & 1.000 & 0.559 & 0.780 & 5 \\
\hline 5 & 851.31 & 684.26 & 0.909 & 1.000 & 0.091 & 0.000 & 0.847 & 1.000 & 0.923 & 2 \\
\hline 6 & 850.58 & 674.20 & 0.904 & 0.854 & 0.096 & 0.146 & 0.839 & 0.775 & 0.807 & 4 \\
\hline 7 & 848.93 & 666.42 & 0.892 & 0.742 & 0.108 & 0.258 & 0.822 & 0.660 & 0.741 & 8 \\
\hline 8 & 727.27 & 615.12 & 0.000 & 0.000 & 1.000 & 1.000 & 0.333 & 0.333 & 0.333 & 9 \\
\hline 9 & 847.07 & 681.02 & 0.878 & 0.953 & 0.122 & 0.047 & 0.804 & 0.914 & 0.859 & 3 \\
\hline
\end{tabular}

The main effect plots for the signal to noise ratio $(\mathrm{S} / \mathrm{N})$ and the means corresponding to the values of the GRGs have been computed using Minitab 17 software. The larger the better function is selected for determining the $\mathrm{S} / \mathrm{N}$ ratio and the means. Figure 5 shows the main effects plot of the $\mathrm{S} / \mathrm{N}$ ratio for the GRGs. The plot reveals that $\mathrm{S}$ the optimal process parameter combination is Voltage (MIG) 2 - Current (TIG) $3-$ Gas flow rate 3, i.e voltage $(\mathrm{MIG})=25 \mathrm{~V}$, current $(\mathrm{TIG})=180 \mathrm{~A}$, gas flow rate $=19 \mathrm{~L} / \mathrm{mm}$. 


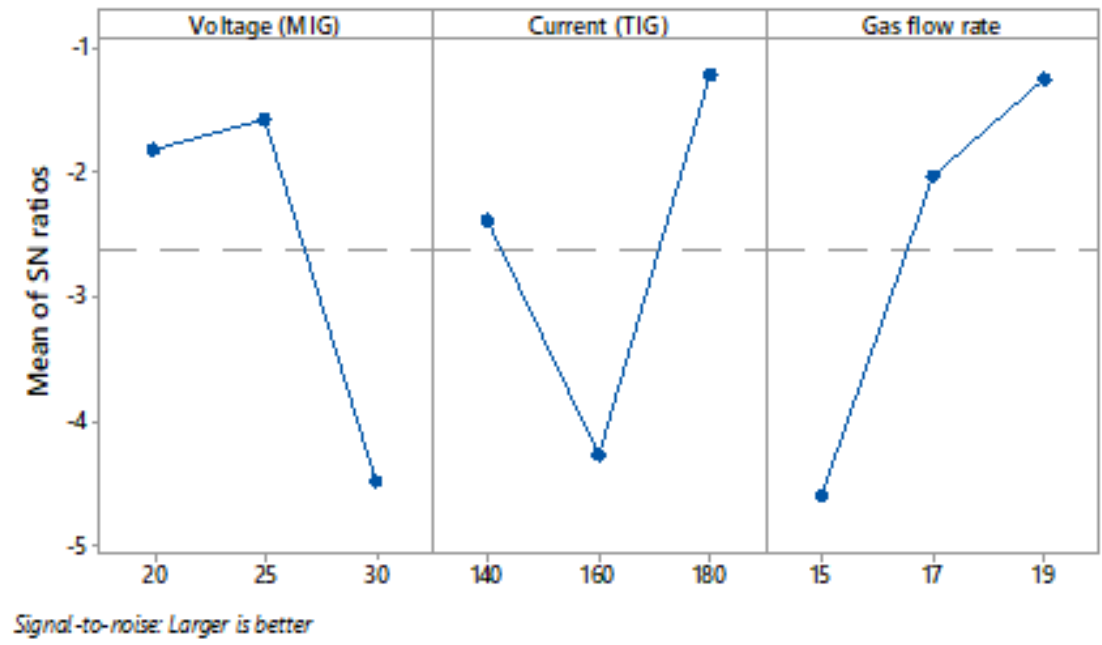

Figure 5. Main effects plots for $\mathrm{S} / \mathrm{N}$ rate

The main effects for means for each input parameter at each level are presented in Table 7 and Figure 6.

Table 7. Response table for means

\begin{tabular}{llll}
\hline Level & Voltage (MIG) & Current (TIG) & Gas flow rate \\
\hline 1 & 0.8173 & 0.7598 & 0.6330 \\
2 & 0.8366 & 0.6662 & 0.7936 \\
3 & 0.6445 & 0.8724 & 0.8717 \\
Delta (Max-Min) & 0.1921 & & 0.2388 \\
Rank & 3 & 0.2062 & 1
\end{tabular}

The total means for grey relational grade $=0.7661$

The main effects for the means table denote the level of correlation between the reference sequence and the obtained sequence. A higher value signifies a stronger correlation. Table 7 also shows the delta ranking of the parameters. The gas flow rate had the most influence followed by the current (TIG) whereas the voltage (MIG) had the last influence on the responses. 


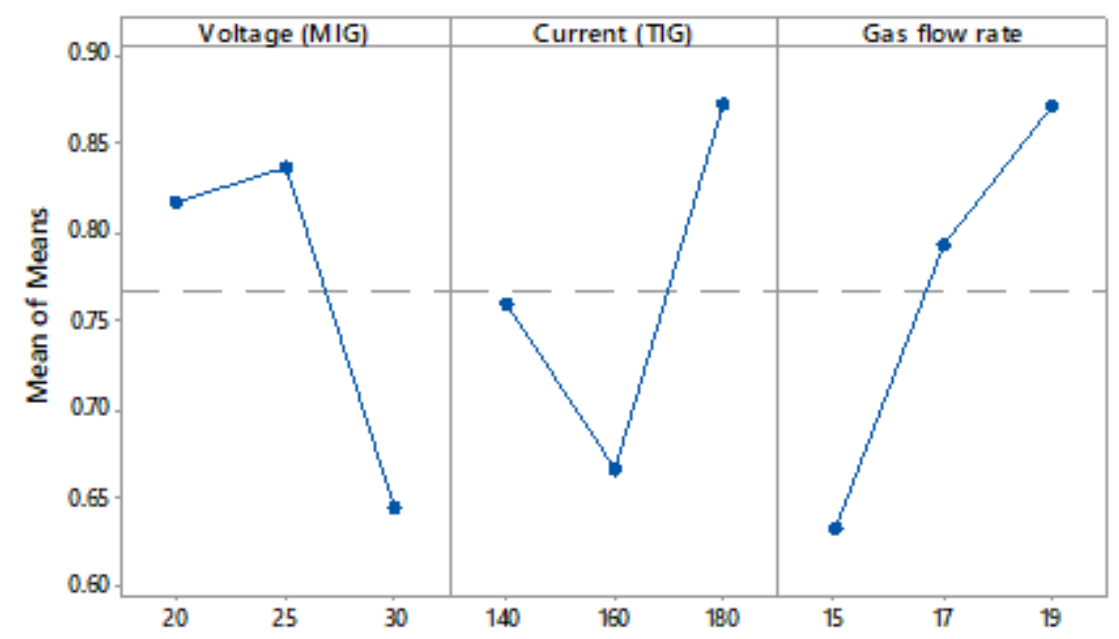

Figure 6. The main effects plot for means

The main effects plot for means indicates that changes in the levels of the process parameters influence the response (GRG). An increase in MIG voltage [voltage (MIG)] from $20 \mathrm{~V}$ to $25 \mathrm{~V}$ increased the GRG value, a further increase in the MIG voltage to $30 \mathrm{~V}$ resulted in a decrease in the GRG. The GRG decreased as the TIG current [current (TIG)] increased from $140 \mathrm{~A}$ to $160 \mathrm{~A}$ and increased greatly to the maximum as the current increases to $180 \mathrm{~A}$. GRG value increased proportionally with an increase in the gas flow rate.

\subsection{Analysis of Variance for the grey relational grades}

Analysis of variance (ANOVA) is adopted to determine the influence of each input process parameter in terms of their respective percentage contribution and level of significance at a specified confidence level. Table 8 shows the ANOVA data generated using the GRG values. The gas flow rate had the most influence on the response with a percentage contribution of $39.77 \%$, followed by the TIG welding current [current (TIG)] with a percentage contribution of $26.69 \%$, the MIG welding [voltage (MIG)] had the least contribution of $21.47 \%$ on the response. It is worthy to note that at a $95 \%$ confidence level none of the input process parameters was insignificant.

Table 8. ANOVA for the transformed response

\begin{tabular}{llllllll}
\hline Source & DF & Seq SS & Adj SS & Adj MS & F-Value & P-Value & Contribution \\
\hline Voltage (MIG) & 2 & 0.03724 & 0.03724 & 0.01862 & 1.78 & 0.360 & $21.47 \%$ \\
Current (TIG) & 2 & 0.04629 & 0.04629 & 0.02315 & 2.21 & 0.311 & $26.69 \%$ \\
Gas flow rate & 2 & 0.06898 & 0.06898 & 0.03449 & 3.29 & 0.233 & $39.77 \%$ \\
Error & 2 & 0.02094 & 0.02094 & 0.01047 & & & $12.07 \%$ \\
Total & 8 & 0.17346 & & & & & 100 \\
\hline
\end{tabular}




\subsection{Mathematical models results}

Mathematical equations have been established for the ultimate tensile strength and the yield strength based on the input parameters. The accuracy of the model developed has been determined by the coefficient of determination $\mathrm{R}^{2}$. The closer the $\mathrm{R}^{2}$ value is to unity, the more liable the developed regression model. The first-order and second-order regression models for ultimate tensile strength have been computed using Minitab 17 software and presented as in Equation (5) and (6). The regression plot and the data points for the experimental values against the predicted values for the first-order and second-order regression for tensile strength are presented in Figure 7(a), (b), (c) and (d) respectively. The result shows that the second-order regression gave a higher coefficient of determination $\mathrm{R}^{2}$ of 100\%. A similar result has been reported by Kumar and Singh, (2019).

First-order regression model for Ultimate tensile strength (UTS)

$$
\begin{gathered}
\text { UTS }=774-4.69 \text { Voltage }(M I G)-0.034 \text { Current }(T I G) \\
+11.1 \text { Gas flow rate }
\end{gathered}
$$

$R^{2}=43.6 \%$

Second-order regression model for Ultimate tensile strength (UTS)

$U T S=1566-11.45 V-21.12 C+120.1 G-0.9601 V^{2}+0.06884 C^{2}-5.613 G^{2}-$ $0.004938 V * C+3.268 V * G$

(6)

$R^{2}=100 \%$

Where

Where $\mathrm{V}=$ voltage $(\mathrm{MIG}), \mathrm{C}=$ Current $(\mathrm{TIG}), \mathrm{G}=\mathrm{Gas}$ flow rate, $\mathrm{V}^{2}=$ voltage squared, $\mathrm{C}^{2}=$ Current squared, $\mathrm{G}^{2}=\mathrm{Gas}$ flow rate squared, $\mathrm{V} * \mathrm{C}=$ Voltage $(\mathrm{MIG}){ }^{*}$ Current $(\mathrm{TIG})$ and $\mathrm{V}^{*} \mathrm{G}=$ Voltage $(\mathrm{MIG}) *$ Gas flow rate. 


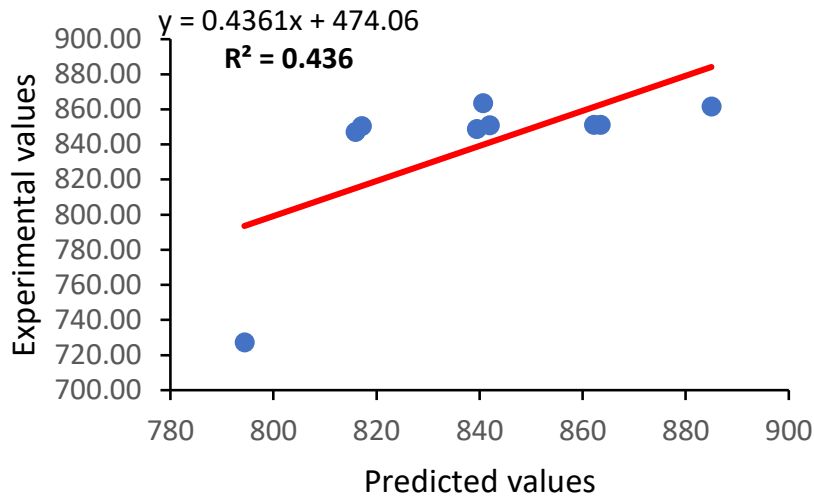

(a)
- Experimental vs Predicted UTS 1st order

Linear (Experimental vs Predicted UTS 1st order

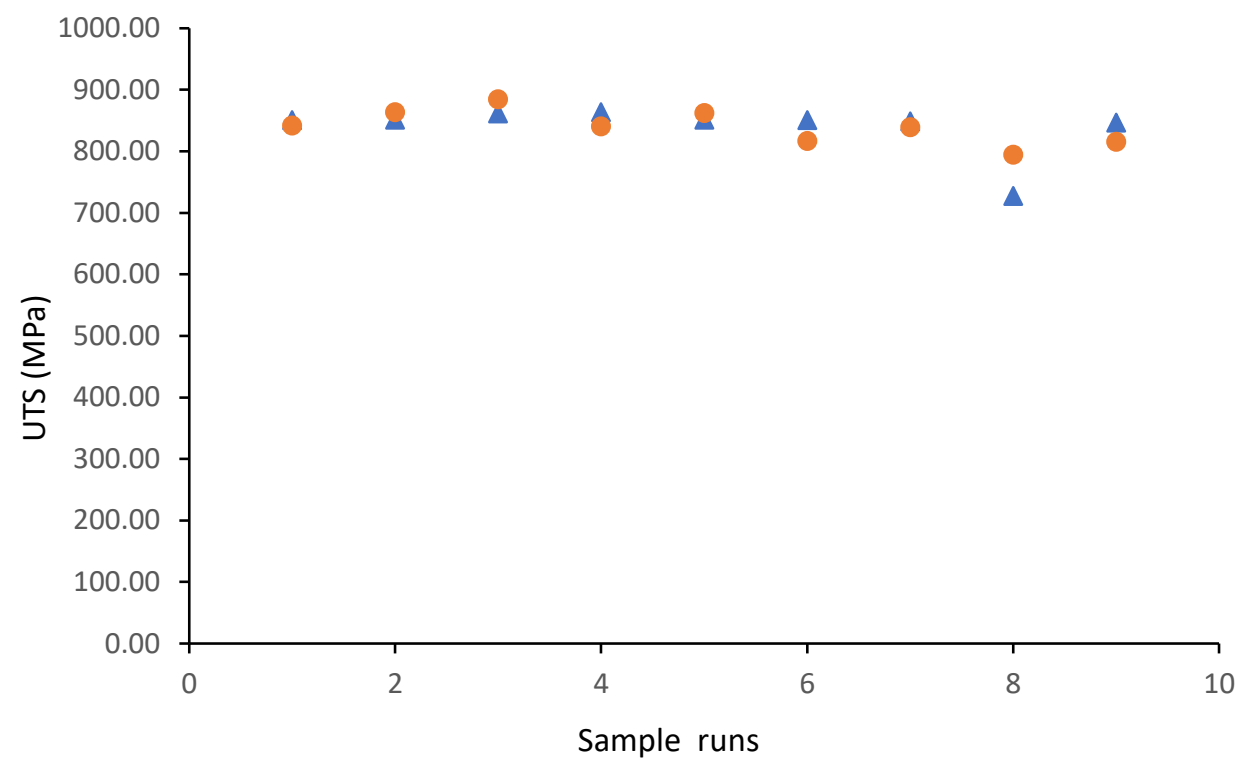

Experimental UTS

Predicted UTS

(b) 


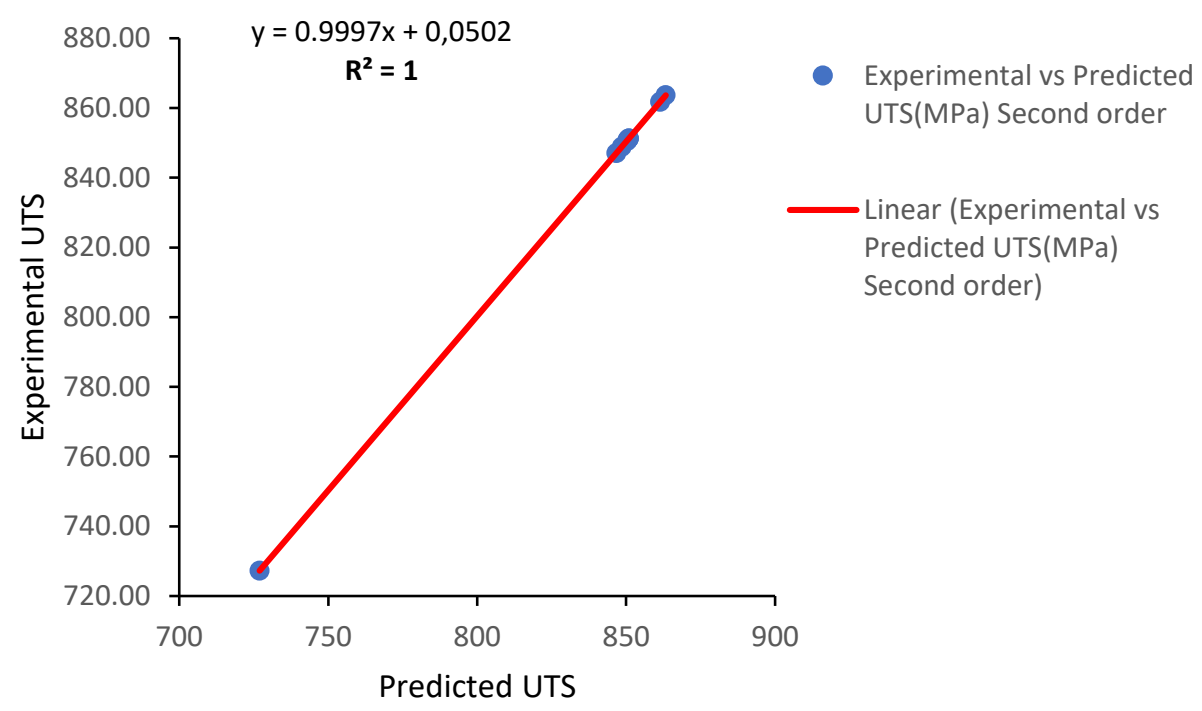

(c) Experimental vs Predicted UTS(MPa) - second order

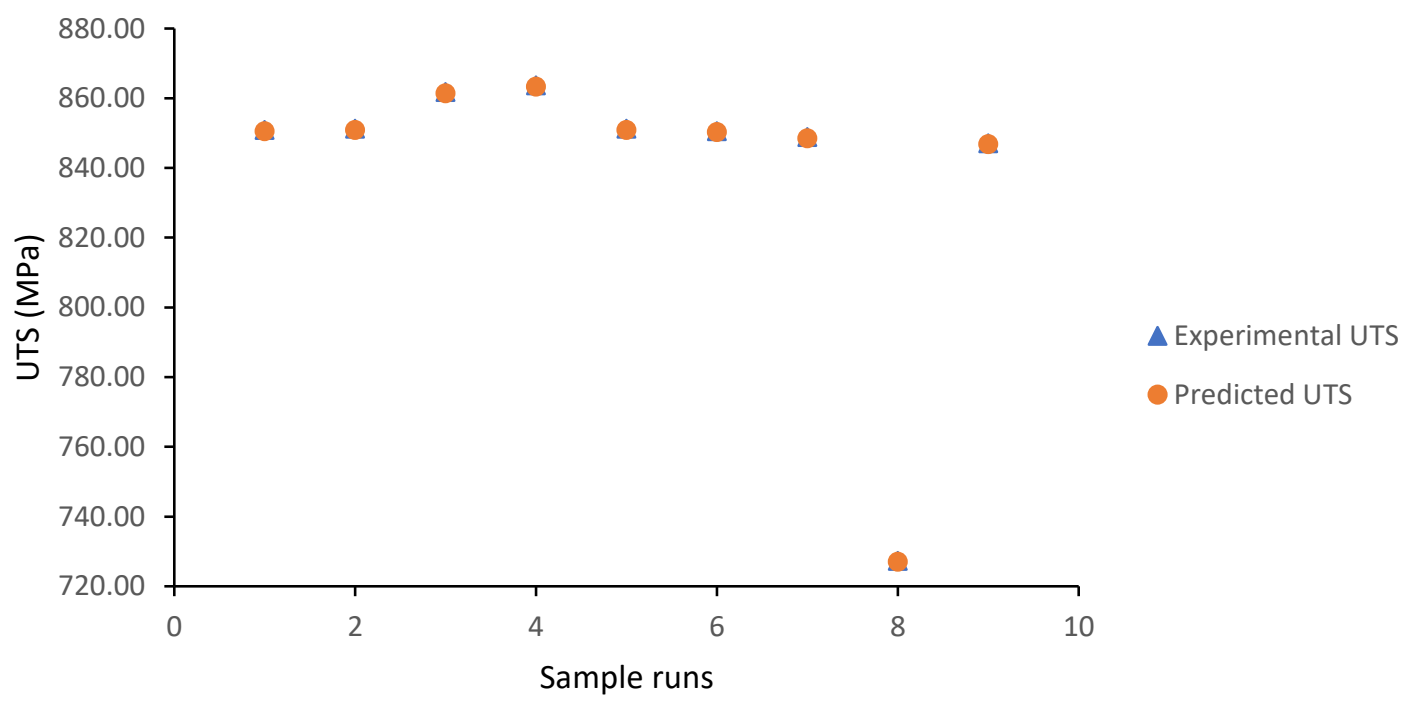

(d)

Figure 7. Graphical representations of regression plots and data points for the experimental against predicted values of ultimate tensile strength. [(a) first-order regression plot, (b) first-order experimental vs predicted data points (UTS), (c) second regression plot,(d) second-order experimental vs predicted data points (UTS)].

Likewise, the first and second-order regression equation for yield strength is also represented in Equation (7) and (8). The regression plot and the data points for the experimental values against the 
predicted values for the first-order and second-order regressions for yield strength are presented in Figure 8(a), (b), (c) and (d) respectively.

First-order regression model for YS

$$
\begin{aligned}
\text { UTS }=504.9- & 1.71 \text { Voltage }(M I G)+0.381 \text { Current }(T I G) \\
& +6.28 \text { Gas flow rate }
\end{aligned}
$$

$R^{2}=48.9 \%$

Second-order YS

$$
\begin{aligned}
U T S=1959- & 27.49 V-7.948 C-50.67 G-0.363 V^{2}+0.02017 C^{2}+0.4807 G^{2} \\
& +0.09222 V * C+1.716 V \\
& * G
\end{aligned}
$$

$R^{2}=100 \%$

Where $\mathrm{V}=$ voltage $(\mathrm{MIG}), \mathrm{C}=$ current $(\mathrm{TIG}), \mathrm{G}=$ gas flow rate, $\mathrm{V}^{2}=$ voltage squared, $\mathrm{C}^{2}=$ current squared, $\mathrm{G}^{2}=$ gas flow rate squared, $\mathrm{V}^{*} \mathrm{C}=$ Voltage $(\mathrm{MIG}) *$ Current $(\mathrm{TIG})$ and $\mathrm{V}^{*} \mathrm{G}=$ Voltage $(\mathrm{MIG}) *$ Gas flow rate.

Figure 8(a), (b), (c) and (d) respectively

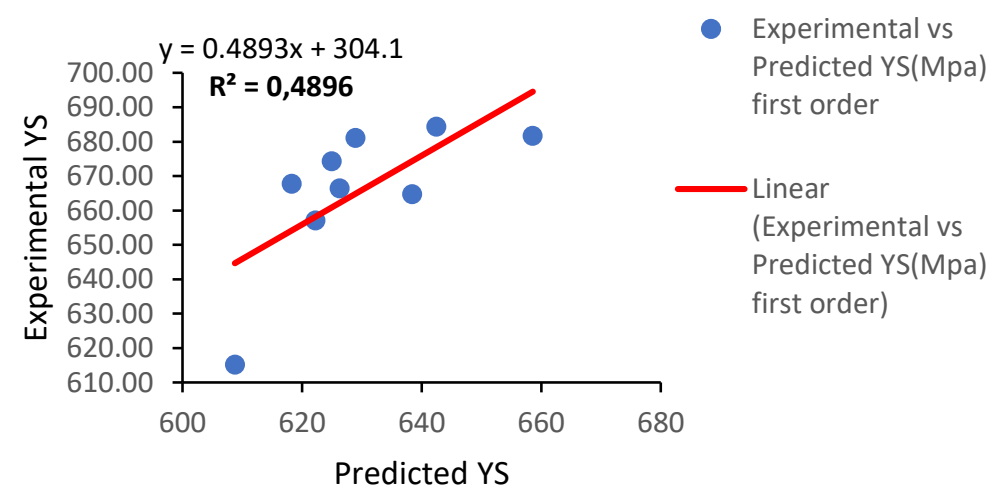

(a) 


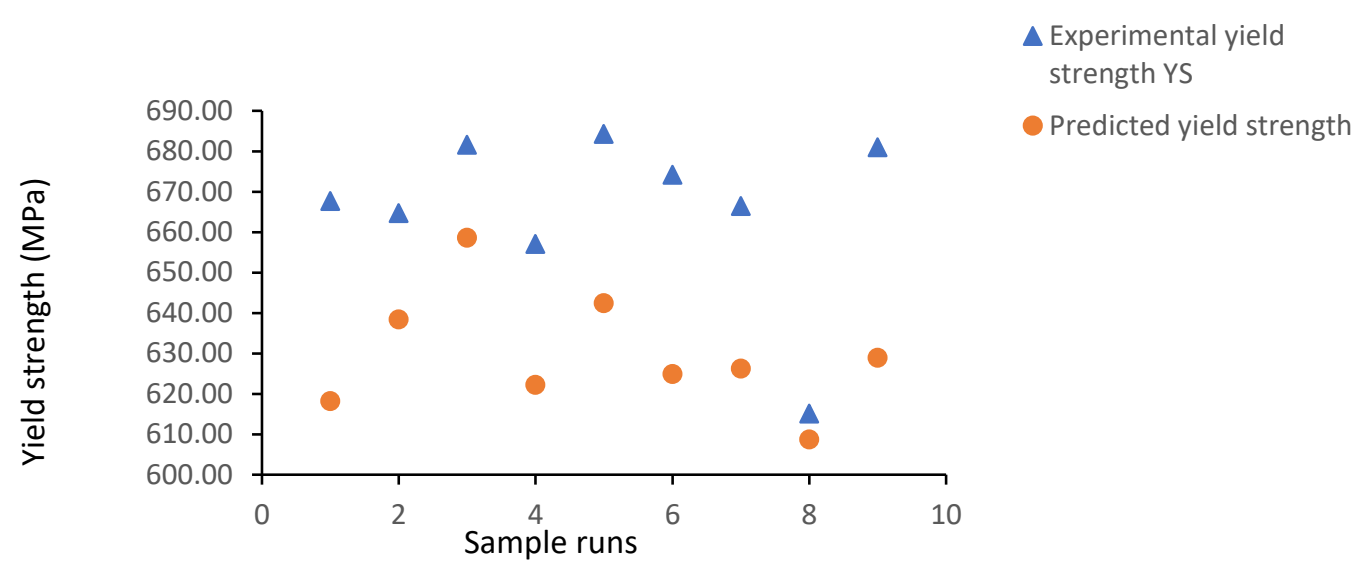

(b)

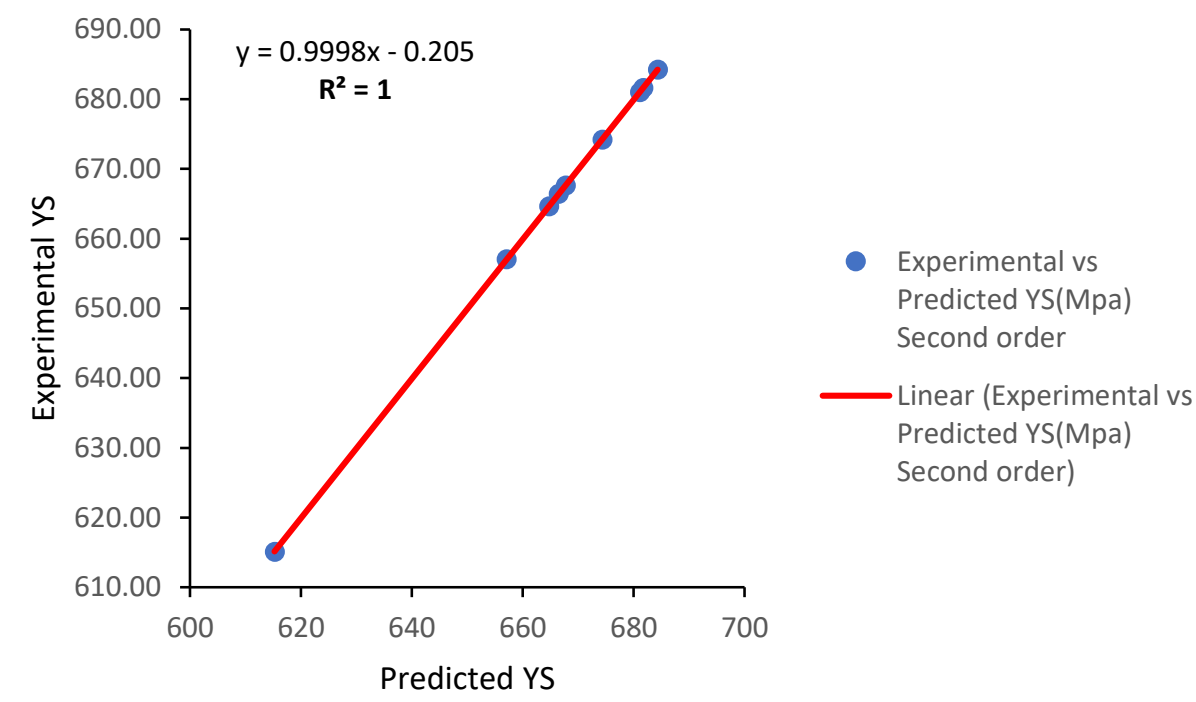

(c) 


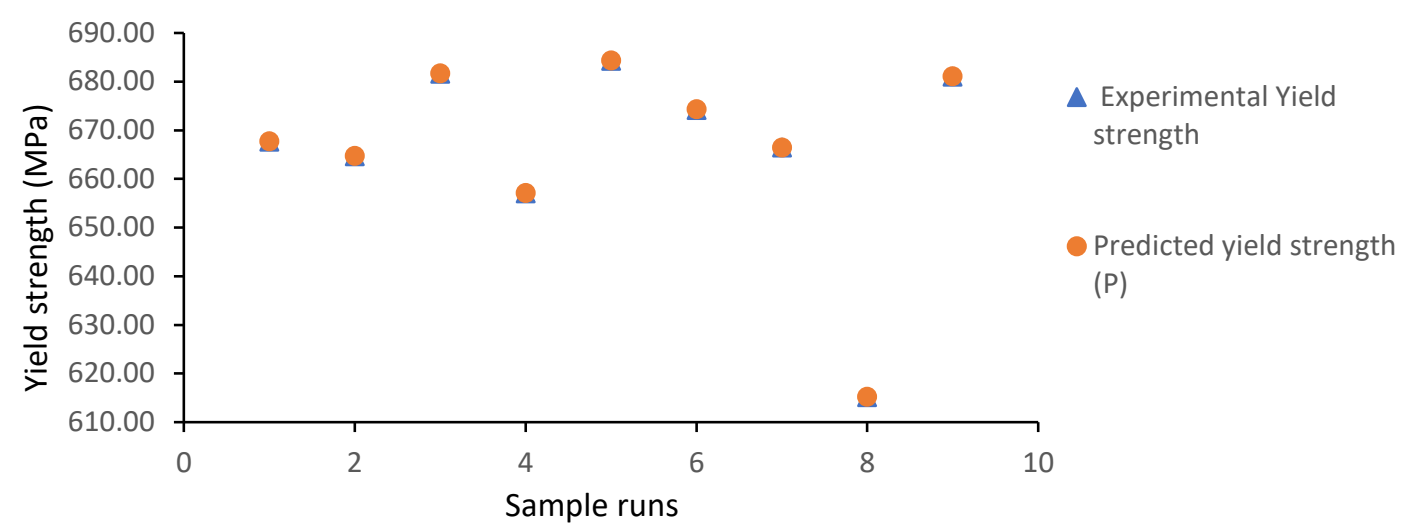

(d)

Figure 8. Graphical representations of regression plots and data points for the experimental against predicted values of yield strength. [(a) first-order regression plot, (b) first-order experimental vs predicted data points (c) second regression plot,(d) second-order experimental vs predicted data points ].

From the above graphs, the coefficient of determination $\mathrm{R}^{2}$ for ultimate tensile strength, and the yield strength were less for the first-order regression models. However, the second-order regression models resulted in a significant increase in the coefficient determination $\mathrm{R}^{2}$ which represents the best fit of the models. The second-order predicted values were very close to the experimental values confirming the adequacy of the models. Hence, the second-order model is said to be statistically significant and can be safely used to predict outcomes before performing the actual experiment.

\subsection{Surface Response plots}

Response surface plots were used to visualize the effects of input process parameters on the individual responses, surface response plots show the variation of a particular response with corresponding levels of the input process parameters. Three response plots for each response have been developed with the help of Minitab 17 software. For each response plot, two input process parameters are represented on the $x$-axis and the y-axis, while the response is represented on the z-axis. The third input parameter is held at a constant value. The response plot for ultimate tensile strength is presented in Figure 9(a), (b), (c), respectively. From figure 9(a), it can be seen that a high value of ultimate tensile strength was obtained at low voltage (MIG) and high current (TIG) while low ultimate tensile strength was obtained at high voltage and low current (TIG). Figure 9(b) shows that high ultimate tensile strength was obtained at high current (TIG) and high gas flow rate. Low current (TIG) and low gas flow rate resulted in low 
ultimate tensile strength. Figure (c) shows that high ultimate tensile strength was obtained at low voltage (MIG) and a high gas flow rate

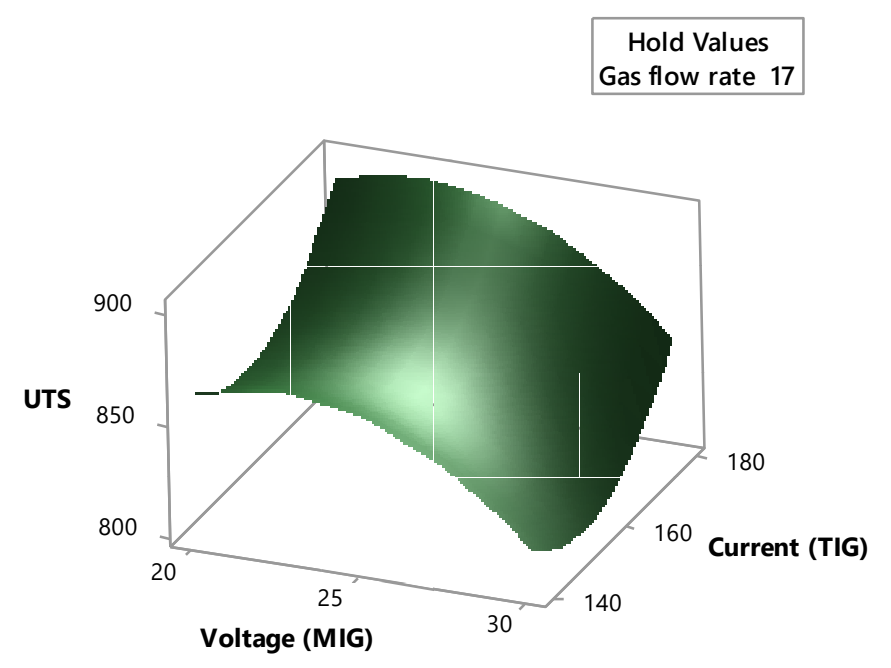

(a)

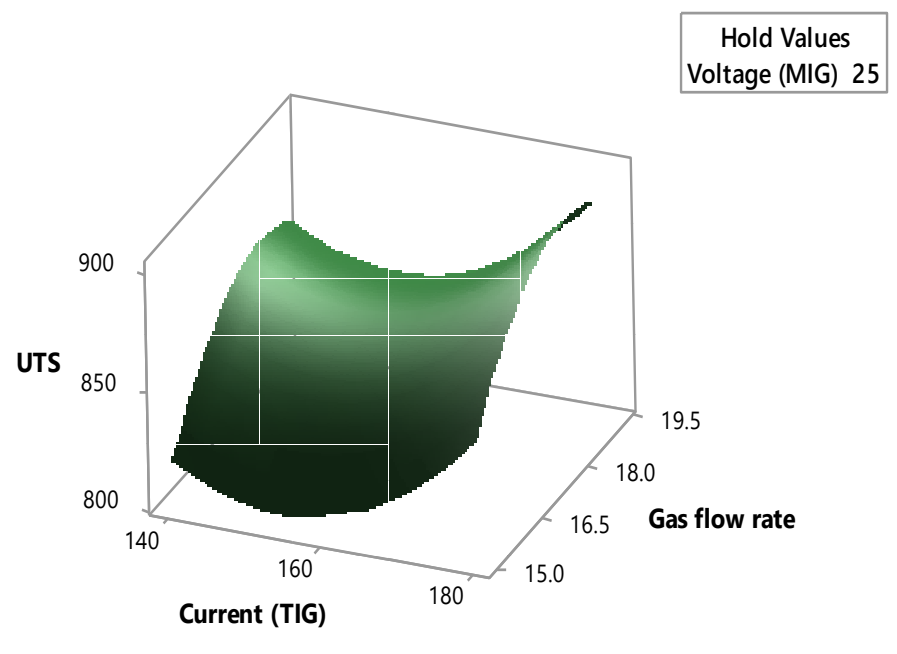

(b) 


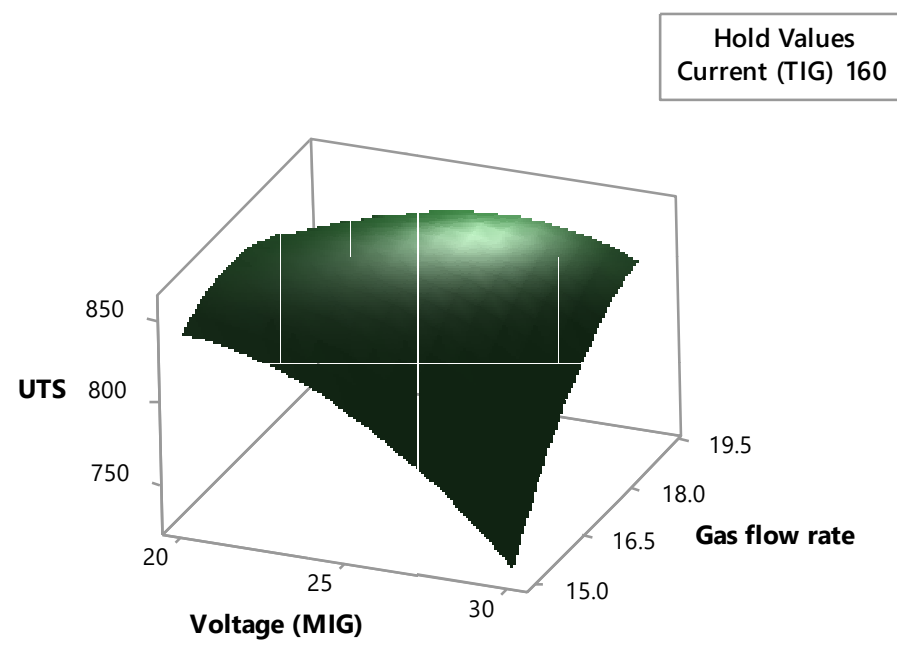

(c)

Figure 9. Response surface plot for UTS. (a) Current (TIG) vs Voltage (MIG), (b) Gas flow rate vs Current (TIG), (c) Voltage (MIG) vs Gas flow rate

Figure 10(a), (b), (c) presents the surface response plots for yield strength. From Figure 10(a), high yield strength was obtained at high current and high gas flow rate. An increase in the current (TIG) and gas flow rate resulted in a corresponding increase in the yield strength. Figure 10(b) shows that low yield strength was obtained at high voltage (MIG) and low gas flow rate while high yield strength was achieved at low voltage and high gas flow rate. Hence yield strength decreases with an increase in voltage (MIG) and increases with increasing gas flow rate. Figure10(c) shows that high yield strength was obtained at low voltage (MIG) and high current (TIG).

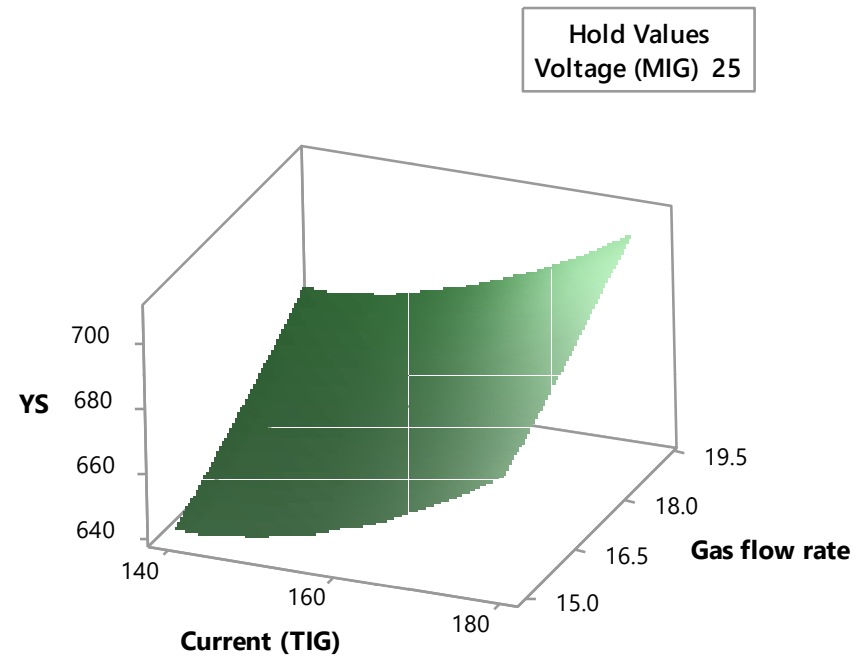

(a) 


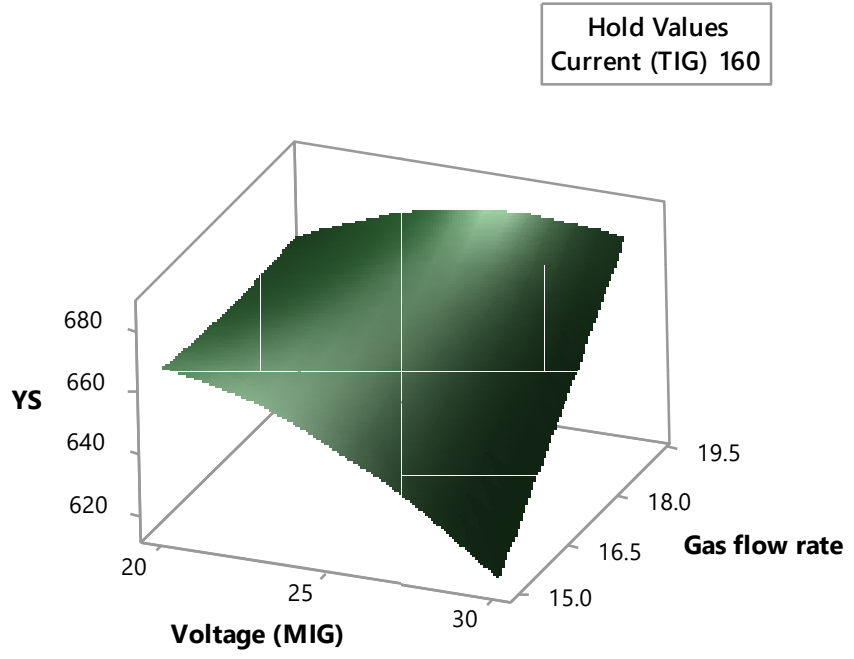

(b)

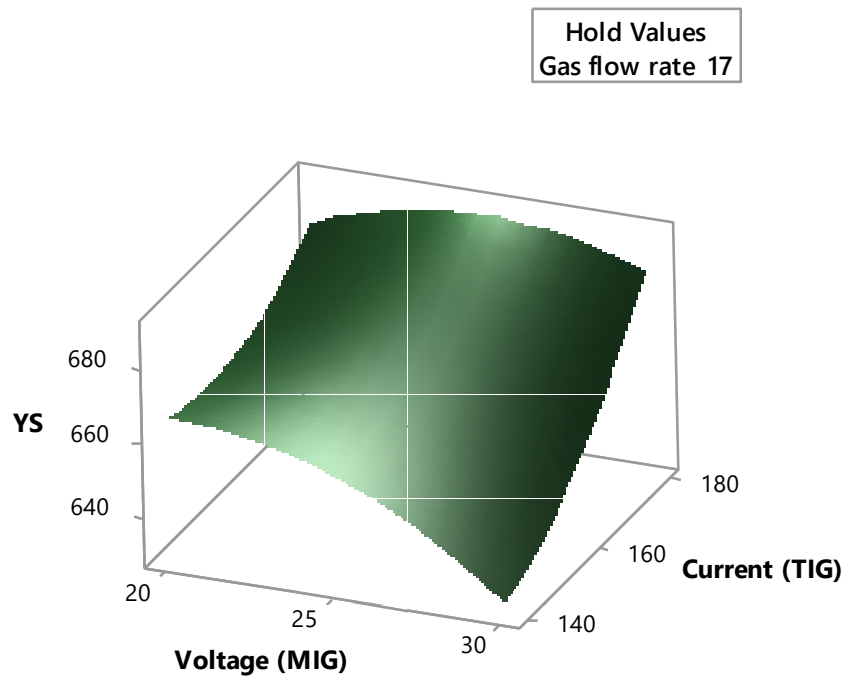

(c)

Figure 10. Response surface plot for UTS. (a) Gas flow rate vs Current(TIG), (b) Gas flow rate vs Voltage (MIG), (c) Current (TIG) vs Voltage (MIG)

\subsection{Confirmation test}

A confirmation experiment was performed with the values of the optimized set of process parameters obtained from the grey relational analysis. i.e Voltage (MIG) 2 - Current (TIG) $\mathbf{3}$ - Gas flow rate 3, which is voltage $(\mathrm{MIG})=25 \mathrm{~V}$, current $(\mathrm{TIG})=180 \mathrm{~A}$, gas flow rate $=19 \mathrm{~L} / \mathrm{mm}$, to validate the predicted data with the experimental data. The experiment carried out with these parameters gives a tensile strength of $872.27 \mathrm{MPa}$ and a yield strength of $688 \mathrm{Mpa}$. The initial parameters which gave the highest GRG base on the larger the better criterion were Voltage (MIG) 1 - Current (TIG) 3 - Gas flow 
rate 3 i.e Voltage (MIG) $20 \mathrm{~V}$, Current (TIG) $180 \mathrm{~A}$, Gas flow rate $19 \mathrm{~L} / \mathrm{mm}$ corresponding to sample run 3. The GRG value for the predicted optimal set of parameters calculated using Equation 10 is 1.0485. The GRG for the confirmation experiment has also been calculated by performing another grey relational analysis using the initial experimental data set plus the experimental results of the confirmation test. The GRG for the confirmation experiment is seen to be 1.000 .

$\hat{y}=y_{m}+\sum_{i=1}^{n}\left(\hat{y}-y_{m}\right)$

where $y_{m}$ is the total mean GRG, $\hat{y}$ is the GRG at the optimal level of each process parameter and $\mathrm{n}$ is the number of significant parameters.

The results of the confirmation test are presented in Table 9. It can the seen that the predicted and experimental GRG values are close and that the grey relational grade of the responses (tensile strength and yield strength is significantly improved $(0.0489)$ by the optimal parametric combination settings.

Table 9. Result of confirmation experiment

\begin{tabular}{llll}
\hline & $\begin{array}{l}\text { Initial } \\
\text { parameters }\end{array}$ & optimal & Optimal parameters from S/N of GRG \\
\cline { 2 - 4 } & & Predicted & Experimental \\
\hline level & Voltage(MIG)1- & Voltage(MIG)2- & Voltage(MIG2- Current(TIG) \\
& Current(TIG)3- & Current(TIG)3 - & $3-$ \\
& Gas flow rate 3 & Gas flow rate 3 & Gas flow rate 3 \\
UTS (MPa) & 861.74 & & 872.27 \\
YS (MPa) & 681.65 & & 688 \\
GRG & 0.9511 & 1.0485 & 1.000 \\
\hline
\end{tabular}

Improvement in $\mathrm{GRG}=0.0489$

\section{Conclusions}

Multi-objective optimization of the TIG/MIG hybrid welding on AISI 1008 mild steel using the greybased Taguchi approach has been investigated. The first and second-order mathematical models have been developed for appropriate parameter settings. The following conclusions have been drawn from the study.

a. AISI 1008 mild steel was successfully welded by the TIG-MIG hybrid welding. The tensile and the yield strength of the welded joints were seen to be higher than those of the parent material.

b. The optimal parametric settings for the multi-objective optimization by the grey based Taguchi method is Voltage (MIG) 2 - Current (TIG) 3 - Gas flow rate 3, i.e Voltage (MIG) $=25 \mathrm{~V}$, Current $($ TIG $)=180 \mathrm{~A}$, gas flow rate $=19 \mathrm{~L} / \mathrm{mm}$. 
c. The second-order mathematical models showed a higher coefficient of determination $\mathrm{R}^{2}$ and representing the best fit of the models, hence the second-order mathematical models are suitable for predicting the ultimate tensile and the yield strength of the TIG-MIG hybrid welded joints.

d. ANOVA result shows that the gas flow rate is the most significant parameter affecting the ultimate tensile and the yield strength of the examined TIG-MIG hybrid welded joints of AISI 1008 mild steel with $39.77 \%$ contribution followed by the TIG welding [current (TIG)] with $26.67 \%$ contribution while MIG welding voltage [voltage (MIG)] had the least contribution of $21.47 \%$.

e. Response surface plots show that high current and gas flow rates favoured both high tensile strength and yield strength. The MIG welding voltage [voltage (MIG)] should be kept minimal to achieve high values of tensile strength and yield strength.

CONFLICTS OF INTEREST: The authors declare that there are no conflicts of interest.

ETHICAL APPROVAL: Not applicable

CONSENT TO PARTICIPATE: Not Applicable

CONSENT TO PUBLISH: All authors consent to the publication of the manuscript.

CODE AVAILABILITY: Not Applicable

AUTHORS CONTRIBUTION: SCA-research conception, writing of original manuscript, literature review, experimental work, OSF-Data analysis, review and proof reading of manuscript, SAA-proof reading of manuscript and review. ETA- proofreading of manuscript, literature review, data analysis, materials. NM-review and data analysis.

FUNDING: No funding for this research

AVAILABILITYOF DATA: The findings of this study are available within the article.

\section{References}

Avinash, S., Balram, Y., Sridhar Babu, B., Venkatramana, G., 2019. Multi-response optimization of pulse TIG welding process parameters of welds AISI 304 and Monel 400 using grey relational analysis. Mater. Today Proc. 19, 296-301. https://doi.org/10.1016/j.matpr.2019.07.211

Cheng, Z., Huang, J., Ye, Z., Chen, Y., Yang, J., Chen, S., 2019. Microstructures and mechanical properties of copper-stainless steel butt-welded joints by MIG-TIG double-sided arc welding. J. 
Mater. Process. Technol. 265, 87-98. https://doi.org/10.1016/j.jmatprotec.2018.10.007

Ding, M., Liu, S.S., Zheng, Y., Wang, Y.C., Li, H., Xing, W.Q., Yu, X.Y., Dong, P., 2015. TIG-MIG hybrid welding of ferritic stainless steels and magnesium alloys with $\mathrm{Cu}$ interlayer of different thickness. Mater. Des. 88, 375-383. https://doi.org/10.1016/j.matdes.2015.09.022

Haq, A.N., Marimuthu, P., Jeyapaul, R., 2008. Multi response optimization of machining parameters of drilling $\mathrm{Al} / \mathrm{SiC}$ metal matrix composite using grey relational analysis in the Taguchi method. Int J Adv Manuf Technol 37, 250-255. https://doi.org/10.1007/s00170-007-0981-4

Ismail, A. AL, Fuhaid, M.S., R.V, M., 2017. An Experimental Analysis on Mechanical Integrity of TIG-MIG Hybrid Weldments. Int. J. Mech. Prod. Eng. 5, 114-117.

Kanemaru, S., Sasaki, T., Sato, T., Era, T., Tanaka, M., 2015. Study for the mechanism of TIG-MIG hybrid welding process. Weld. World 59, 261-268. https://doi.org/10.1007/s40194-014-0205-0

Kang, Z.J., Li, X.F., Zhai, W.G., H., X., Hua, P., Zhou, W., 2018. Laser-Tungsten Inert Gas ( TIG ) Hybrid Welding of 2A14 Aluminium Alloy. Lasers Eng. 39, 243-253.

Khan, S.M., Kumar, V., Mandal, P., Mondal, C. subhas, 2018. Experimental Investigation of Combined TIG-MIG Welding for 304 Stainless Steel Plates Experimental Investigation of Combined TIG-MIG Welding for 304 Stainless Steel Plates, in IOP Conference Series: Materials Science and Engineering. https://doi.org/10.1088/1757-899X/377/1/012067

Kumar, S., Singh, R., 2019. Investigation of tensile properties of shielded metal arc weldments of AISI 1018 mild steel with preheating process. Mater. Today Proc. 26, 209-222. https://doi.org/10.1016/j.matpr.2019.10.167

Liming, L., Jifeng, W., Gang, S., 2004. Hybrid laser-TIG welding, laser beam welding and gas tungsten arc welding of AZ31B magnesium alloy. Materials Science Eng. A 381, 129-133. https://doi.org/10.1016/j.msea.2004.04.044

Liu, F., Tan, C., Gong, X., Wu, L., Chen, B., Song, X., 2020. A comparative study on microstructure and mechanical properties of HG785D steel joint produced by hybrid laser-MAG welding and laser welding. Opt. Laser Technol. 128, 106247. https://doi.org/10.1016/j.optlastec.2020.106247

Mathew, M., Rajendrakumar, P.K., 2011. Optimization of process parameters of boro-carburized low carbon steel for tensile strength by Taguchi method with grey relational analysis. Mater. Des. 32, 3637-3644. https://doi.org/10.1016/j.matdes.2011.02.007

Meng, X., Qin, G., Zhang, Y., Fu, B., Zou, Z., 2014. High-speed TIG-MAG hybrid arc welding of mild steel plate. J. Mater. Process. Tech. 214, 2417-2424. https://doi.org/10.1016/j.jmatprotec.2014.05.020 
Moradi, M., Ghoreishi, M., Khorram, A., 2018. Process and outcome comparison between laser, tungsten inert gas (TIG) and laser-TIG hybrid welding. Lasers Eng. 39, 379-391.

Schneider, C., Lisboa, C., Silva, R., Lermen, R., 2017. Optimizing the Parameters of TIG-MIG/MAG Hybrid Welding on the Geometry of Bead Welding Using the Taguchi Method. J. Manuf. Mater. Process. 1, 14. https://doi.org/10.3390/jmmp1020014

Somani, C.A., Lalwani, D.I., 2019. Experimental investigation of TIG-MIG hybrid welding process on austenitic stainless steel. Mater. Today Proc. 18, 4826-4834. https://doi.org/10.1016/j.matpr.2019.07.472

Srirangan, A.K., Paulraj, S., 2016. Multi-response optimization of process parameters for TIG welding of Incoloy $800 \mathrm{HT}$ by Taguchi grey relational analysis. Eng. Sci. Technol. an Int. J. 19, 811-817. https://doi.org/10.1016/j.jestch.2015.10.003

Wakchaure, K.N., Thakur, A.G., Gadakh, V., Kumar, A., 2018. Multi-Objective Optimization of Friction Stir Welding of Aluminium Alloy 6082-T6 Using hybrid Taguchi-Grey Relation Analysis- ANN Method. Mater. Today Proc. 5, 7150-7159. https://doi.org/10.1016/j.matpr.2017.11.380

Wang, H., Liu, X., Liu, L., 2020. Research on Laser-TIG Hybrid Welding of 6061-T6 Aluminum Alloys Joint and Post Heat Treatment. Metals (Basel). 10, 130.

Yan, J., Gao, M., Zeng, X., 2010. Study on microstructure and mechanical properties of 304 stainless steel joints by TIG, laser and laser-TIG hybrid welding. Opt. Lasers Eng. 48, 512-517. https://doi.org/10.1016/j.optlaseng.2009.08.009

Ye, Z., Huang, J., Gao, W., Zhang, Y., Cheng, Z., Chen, S., Yang, J., 2017. Microstructure and mechanical properties of 5052 aluminium alloy/mild steel butt joint achieved by MIG-TIG double-sided arc welding-brazing. Mater. Des. 123, 69-79. https://doi.org/10.1016/j.matdes.2017.03.039

Zhang, Y., Huang, J., Ye, Z., Cheng, Z., 2017. An investigation on butt joints of Ti6Al4V and 5A06 using MIG / TIG double-side arc welding-brazing. J. Manuf. Process. 27, 221-225. https://doi.org/10.1016/j.jmapro.2017.05.010

Zhang, Y., Huang, J., Ye, Z., Cheng, Z., Yang, J., Chen, S., 2018. Influence of welding parameters on the IMCs and the mechanical properties of Ti/Al butt joints welded by MIG/TIG double-sided arc welding-brazing. J. Alloys Compd. 747, 764-771. https://doi.org/10.1016/j.jallcom.2018.03.119

Zhou, Y. Bin, Fang, D.S., Liu, L.M., 2017. Root welding of V-groove thick plate without backing 
plate by MAG-TIG double-arc welding. Int. J. Precis. Eng. Manuf. 18, 623-628.

https://doi.org/10.1007/s12541-017-0074-8

Zhu, Z., Ma, X., Wang, C., Mi, G., 2020. Grain refinement and orientation alternation of $10 \mathrm{~mm} \mathrm{316L}$ welds prepared by magnetic field-assisted narrow gap laser-MIG hybrid welding. Mater.

Charact. 164, 110311. https://doi.org/10.1016/j.matchar.2020.110311

Zong, R., Chen, J., Wu, C., 2019. A comparison of TIG-MIG hybrid welding with conventional MIG welding in the behaviors of arc, droplet and weld pool. J. Mater. Process. Tech. 270, 345-355. https://doi.org/10.1016/j.jmatprotec.2019.03.003 
Figures

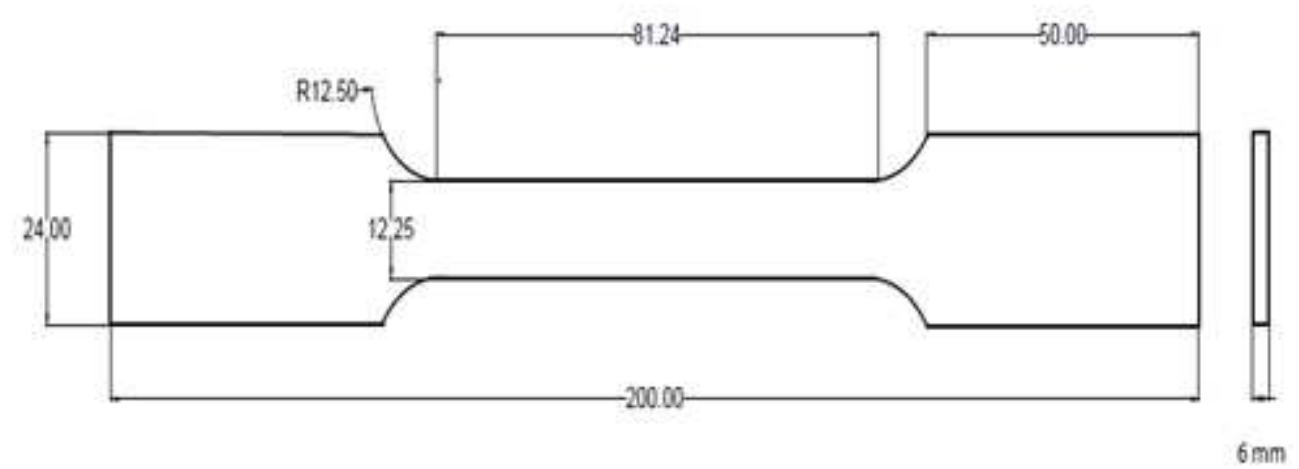

Figure 1

The tensile test specimen sketch

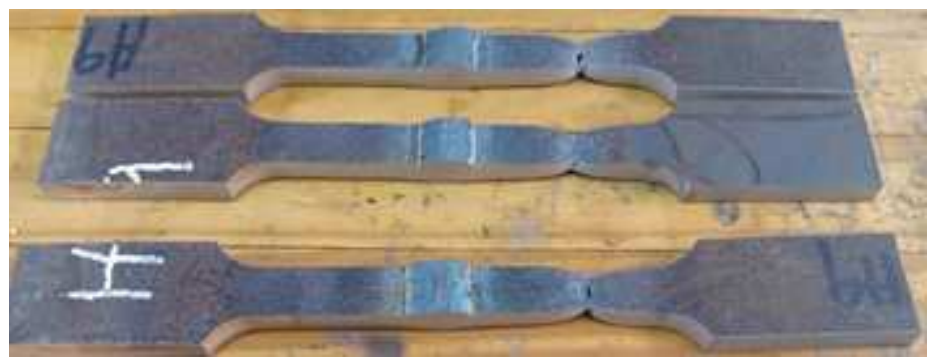

Figure 2

Fractured specimens

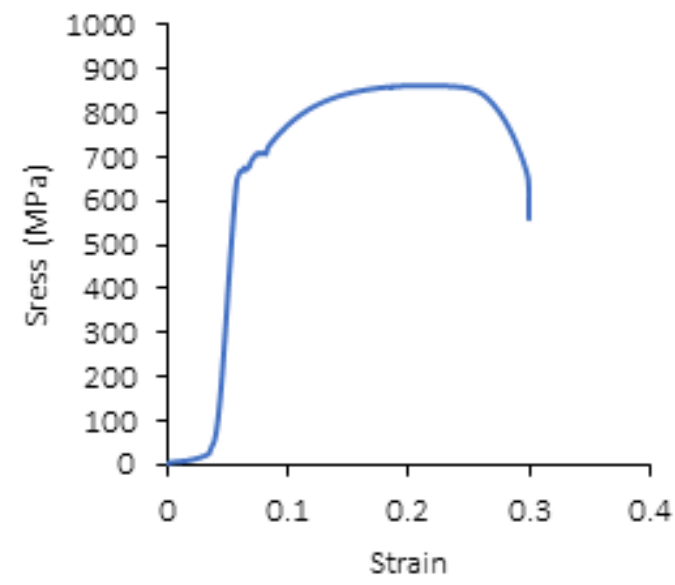

(a)

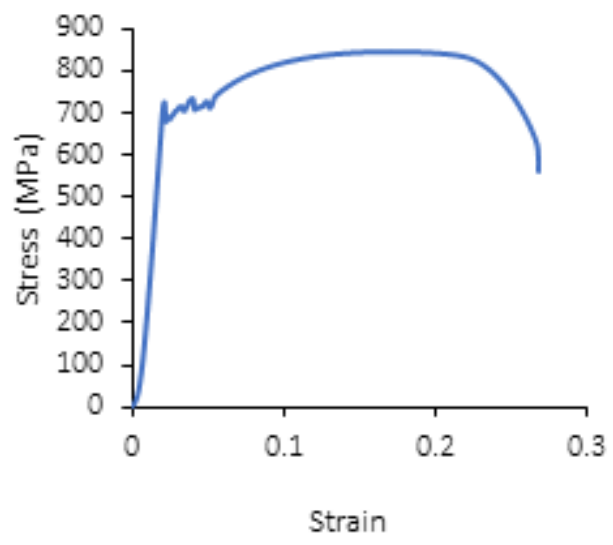

(b)

\section{Figure 3}

Stress-strain curve (a) sample run 4 (b) sample run 7 


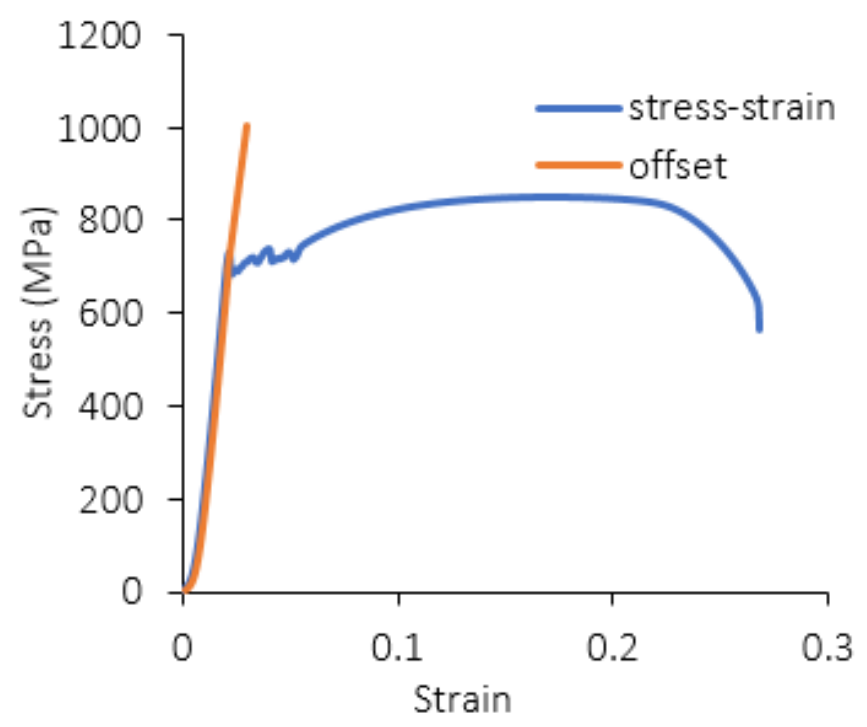

(a)

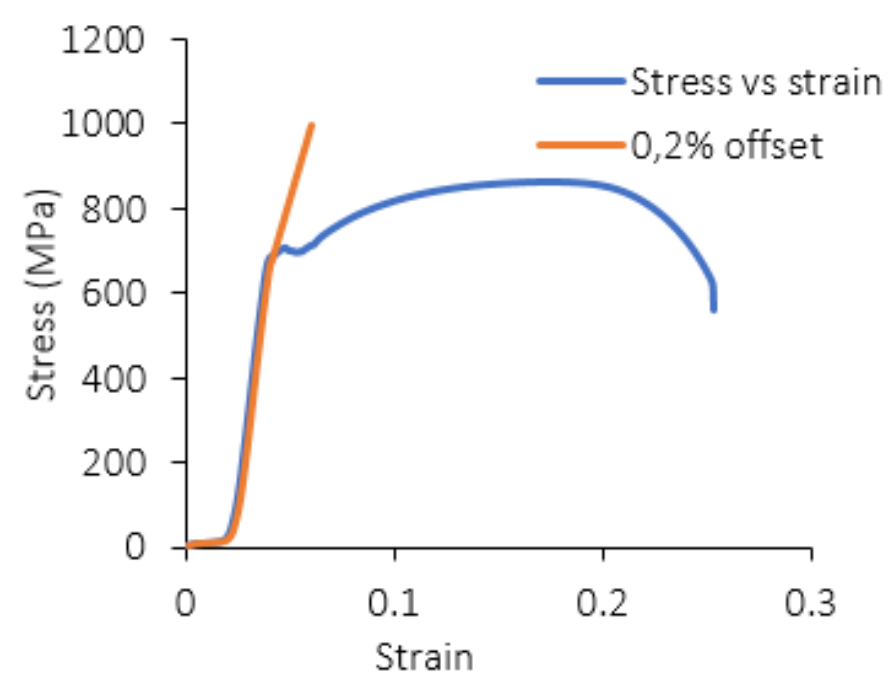

(b)

\section{Figure 4}

Offsets obtained from the original stress-strain curve (a) $0.2 \%$ offset yield strength for sample 7 (b) $0.2 \%$ offset yield strength for sample 3

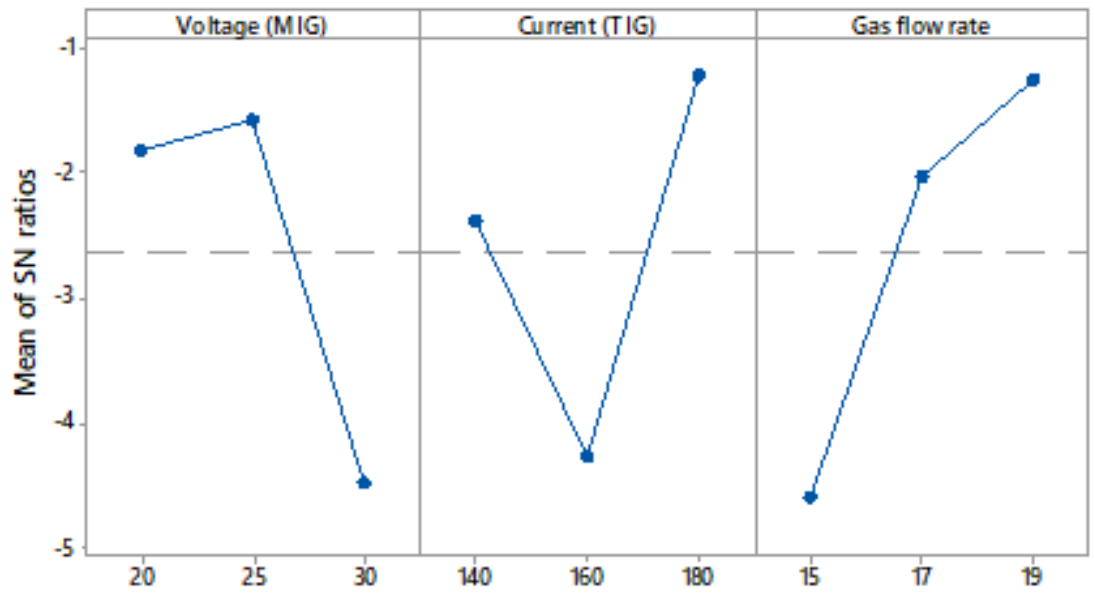

Sygnal-to-roise: Large is better

Figure 5

Main effects plots for $\mathrm{S} / \mathrm{N}$ rate 


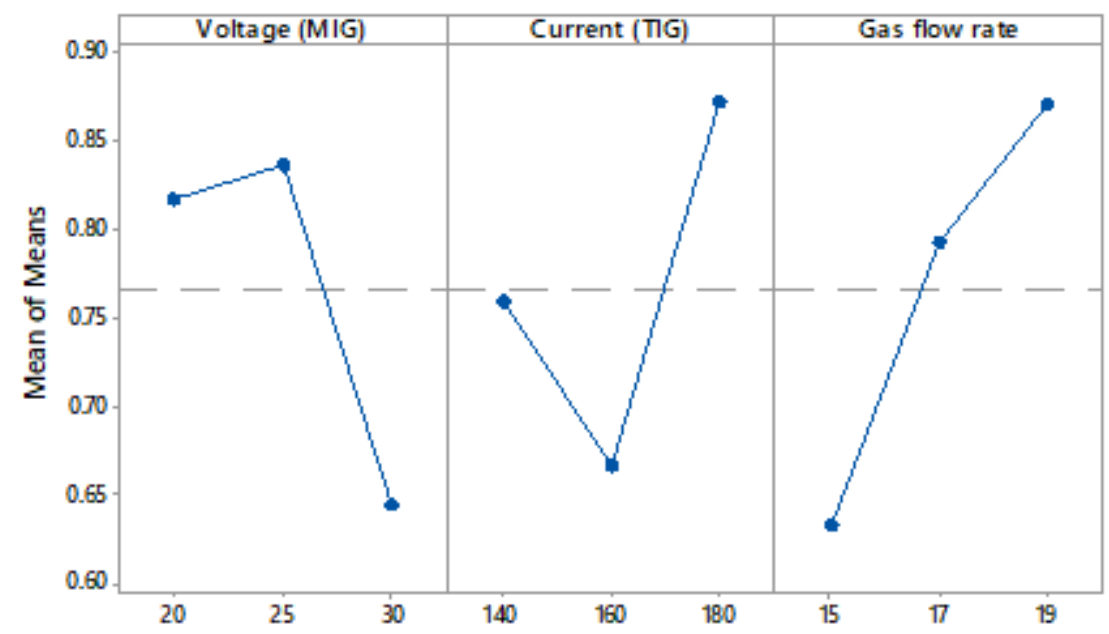

Figure 6

The main effects plot for means

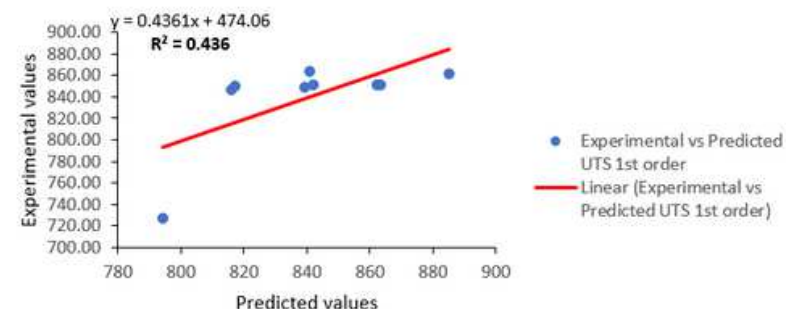

(a)

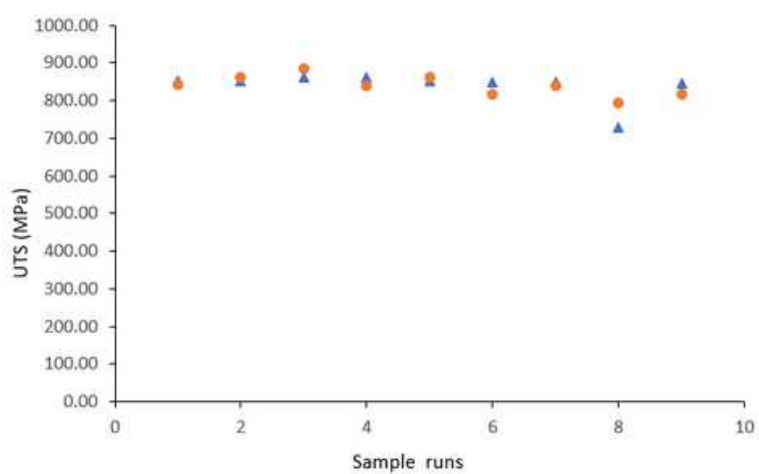

(b)

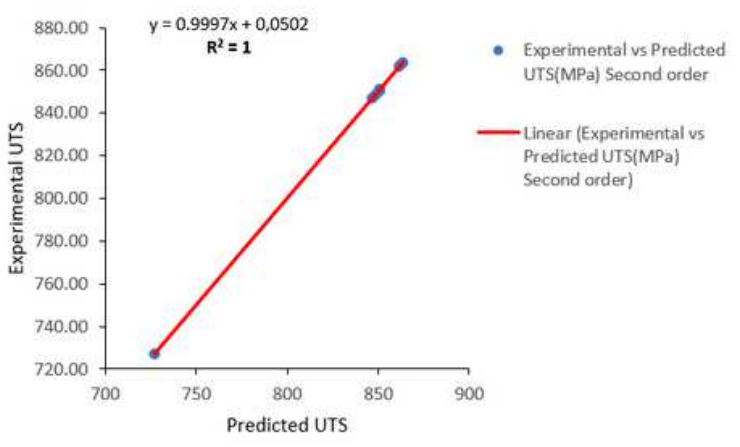

(c) Experimental vs Predicted UTS(MPa) - second order

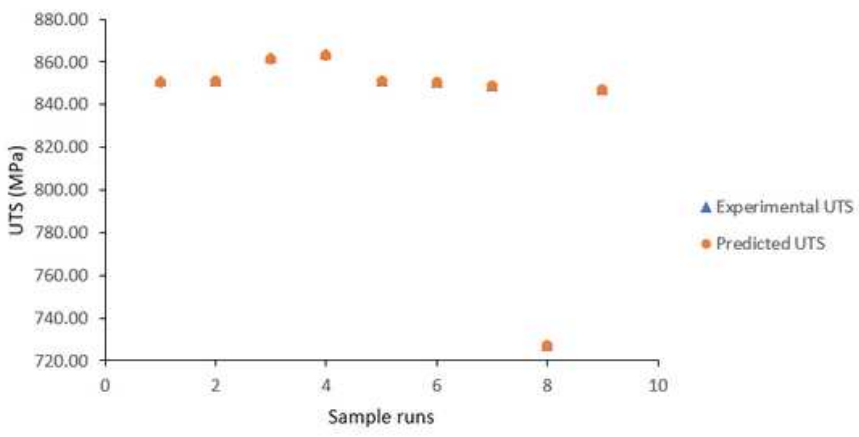

(d)

\section{Figure 7}

Graphical representations of regression plots and data points for the experimental against predicted values of ultimate tensile strength. [(a) first-order regression plot, (b) first-order experimental vs predicted data points (UTS), (c) second regression plot,(d) second-order experimental vs predicted data points (UTS)]. 


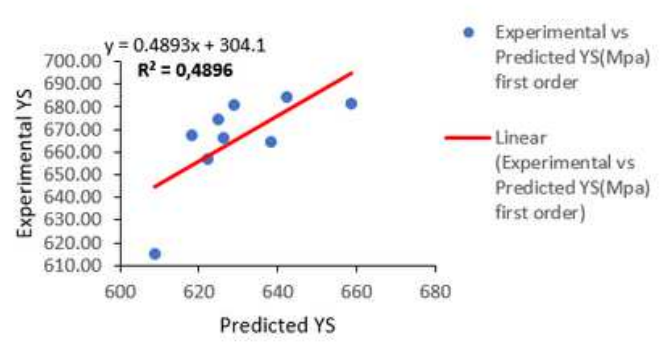

(a)

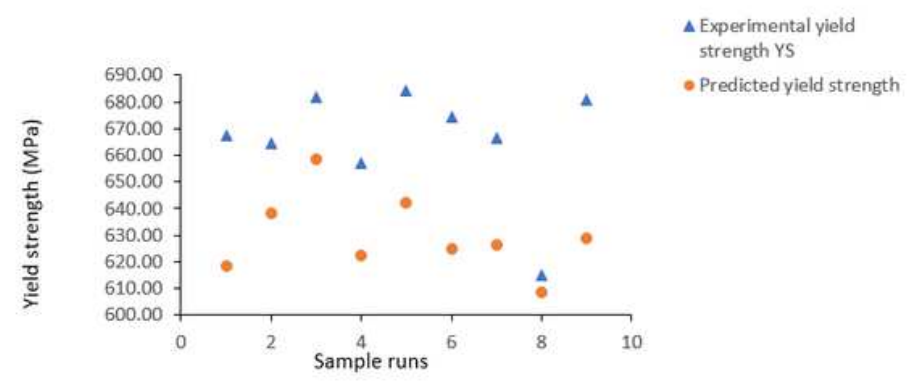

(b)

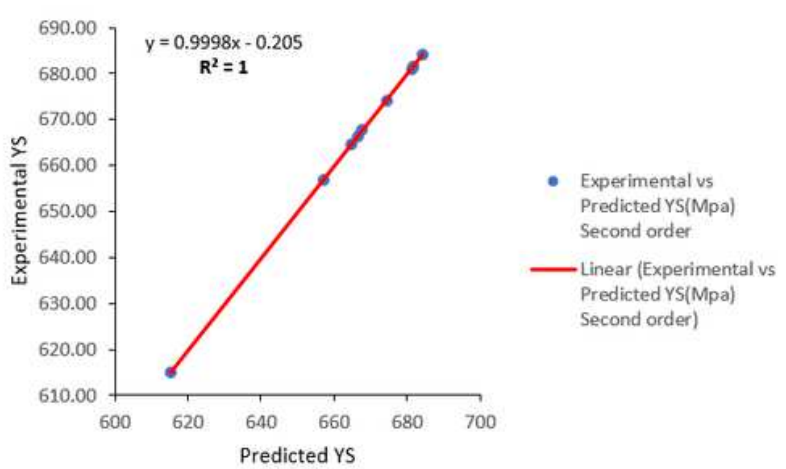

(c)

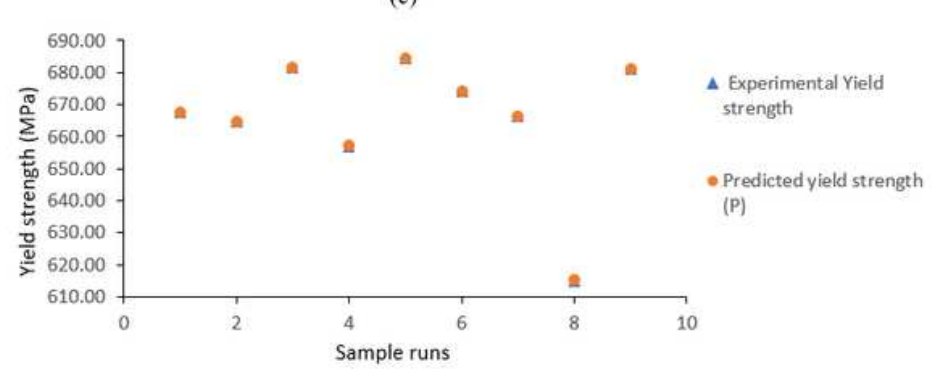

(d)

\section{Figure 8}

Graphical representations of regression plots and data points for the experimental against predicted values of yield strength. [(a) first-order regression plot, (b) first-order experimental vs predicted data points (c) second regression plot,(d) second-order experimental vs predicted data points ].

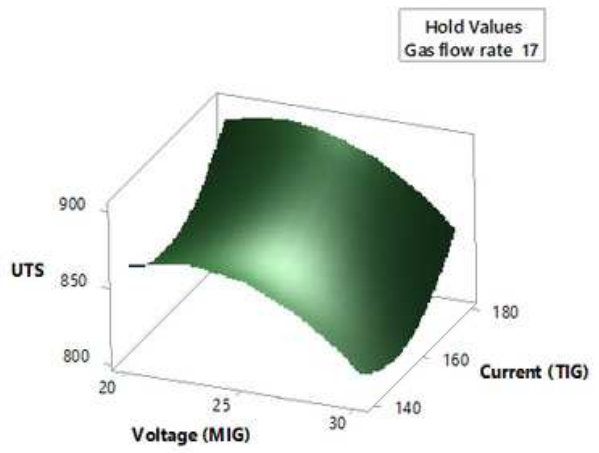

(a)

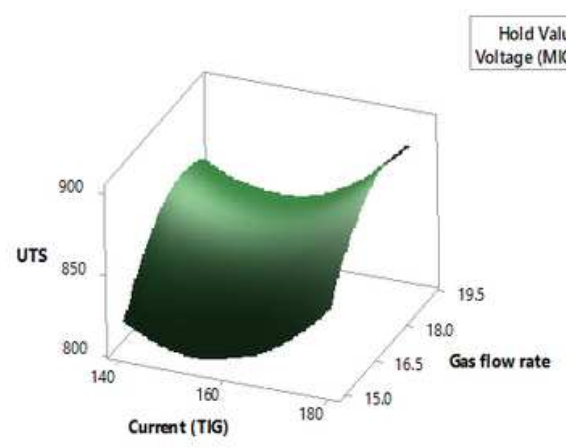

(b)

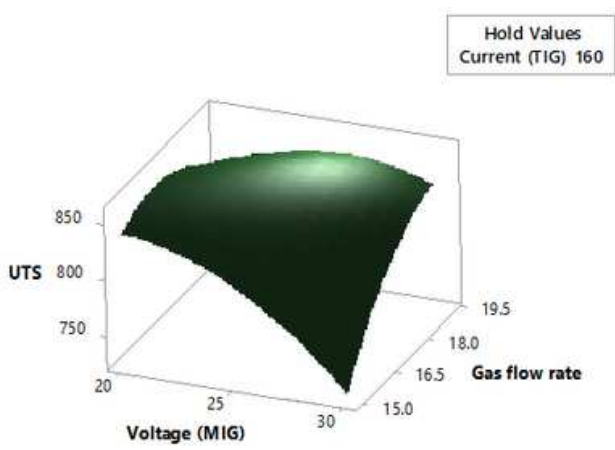

(c)

\section{Figure 9}

Response surface plot for UTS. (a) Current (TIG) vs Voltage (MIG), (b) Gas flow rate vs Current (TIG), (c) Voltage (MIG) vs Gas flow rate 


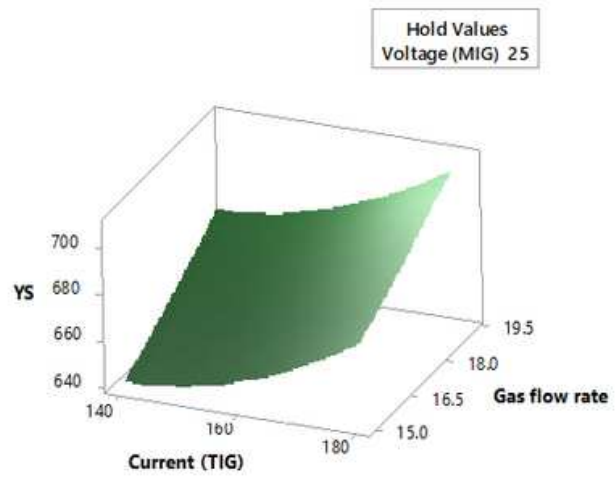

(a)

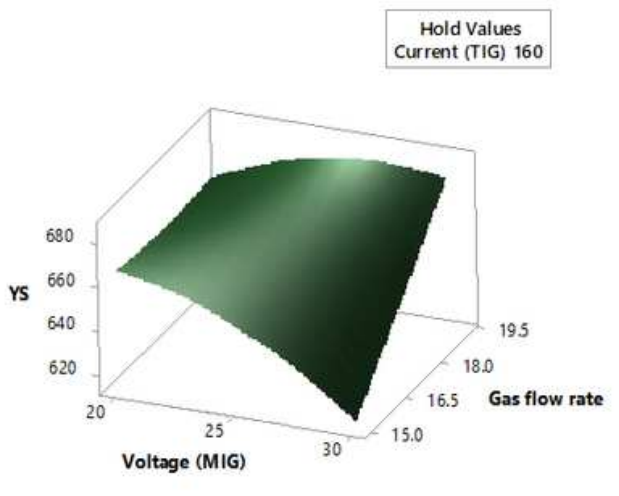

(b)

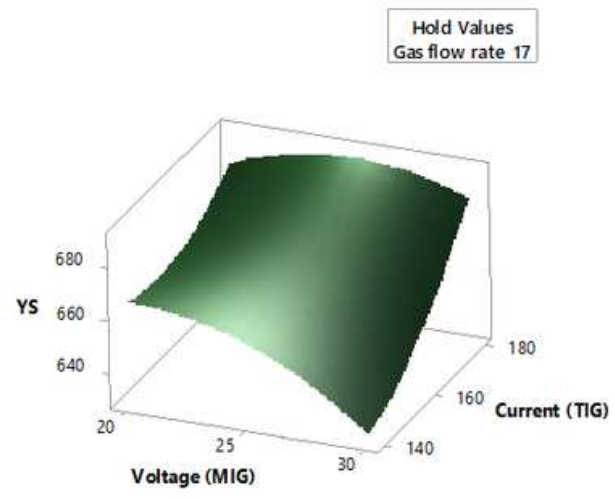

(c)

\section{Figure 10}

Response surface plot for UTS. (a) Gas flow rate vs Current(TIG), (b) Gas flow rate vs Voltage (MIG), (c) Current (TIG) vs Voltage (MIG) 